\title{
Interactions between the Somali Current eddies during the summer monsoon: insights from a numerical study
}

\author{
C. Q. C. Akuetevi ${ }^{1,2}$, B. Barnier ${ }^{1}$, J. Verron ${ }^{1}$, J.-M. Molines ${ }^{1}$, and A. Lecointre ${ }^{3}$ \\ ${ }^{1}$ LGGE, CNRS, Université Grenoble Alpes, 38041 Grenoble, France \\ ${ }^{2}$ LEGI, CNRS, Université Grenoble Alpes, 38041, Grenoble, France \\ ${ }^{3}$ ISTERRE, CNRS, Université Grenoble Alpes, 38041 Grenoble, France \\ Correspondence to: C. Q. C. Akuetevi (cyrille.akuetevi@gmail.com)
}

Received: 30 March 2015 - Published in Ocean Sci. Discuss.: 19 May 2015

Revised: 16 December 2015 - Accepted: 6 January 2016 - Published: 1 February 2016

\begin{abstract}
Three hindcast simulations of the global ocean circulation differing by resolution $\left(1 / 4\right.$ or $\left.1 / 12^{\circ}\right)$ or parametrization or atmospheric forcing are used to describe the interactions between the large anticyclonic eddies generated by the Somali Current system during the Southwest Monsoon. The present investigation of the Somalian coherent eddy structures allows us to identify the origin and the subsequent development of the cyclones flanked upon the Great Whirl (GW) previously identified by Beal and Donohue (2013) in satellite observations and to establish that similar cyclones are also flanked upon the Southern Gyre (SG). These cyclones are identified as potential actors in mixing water masses within the large eddies and offshore the coast of Somalia.

All three simulations bring to light that during the period when the Southwest Monsoon is well established, the SG moves northward along the Somali coast and encounters the GW. The interaction between the SG and the GW is a collision without merging, in a way that has not been described in observations up to now. During the collision the GW is pushed to the east of Socotra Island, sheds several smaller patches of anticyclonic vorticity, and often reforms into the Socotra Eddy, thus proposing a formation mechanism for that eddy. During this process the GW gives up its place to the SG. This process is robust throughout the three simulations.
\end{abstract}

\section{Introduction}

The near-surface circulation of the northwestern Indian Ocean during the summer monsoon is the siege of large and strong anticyclonic eddies produced by recirculation cells of the Somali Current system. In the schematic representation of the typical surface current patterns proposed in the comprehensive review of Schott and McCreary (2001) and updated in Schott et al. (2009, their Fig. 3, see also Fig. 1), the South Equatorial Current (SEC) and the East African Coastal Current (EACC) are supplying the Somali Current (SC), a low-latitude western boundary current flowing northward along the coast of Somalia. A large branch of the EACC turns offshore after crossing the Equator at about 2 or $3^{\circ} \mathrm{N}$ and forms the so-called Southern Gyre (SG), a large anticyclonic retroflection cell with a well-marked wedge of cold upwelled water attached to its northern flank (the southern cold wedge driven by the upwelling favourable winds). According to Beal et al. (2013), this cell re-circulates southward across the Equator to feed into the South Equatorial Counter Current (SECC). In the north, located between the SG and the Island of Socotra (i.e. between 5 and $10^{\circ} \mathrm{N}$ ) is the Great Whirl (GW), a large anticyclone which exhibits very intense swirling currents. Its generation mechanism involves the arrival of remote Rossby waves in spring (see Beal and Donohue, 2013) and an amplification in summer by the monsoon winds via an intensification and a retroflection of the Somali Current. The GW also exhibits an upwelling wedge at its northern flank (the northern cold wedge). A third anticyclonic eddy named the Socotra Eddy (SE) is reported to be frequently present to the east of the Island of Socotra. The 

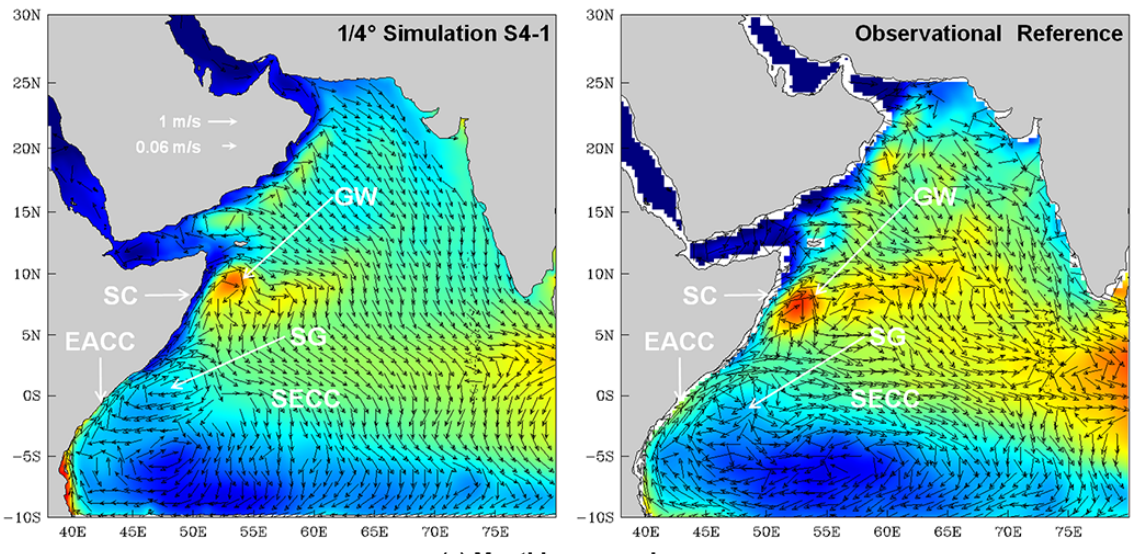

(a) Monthly mean - June
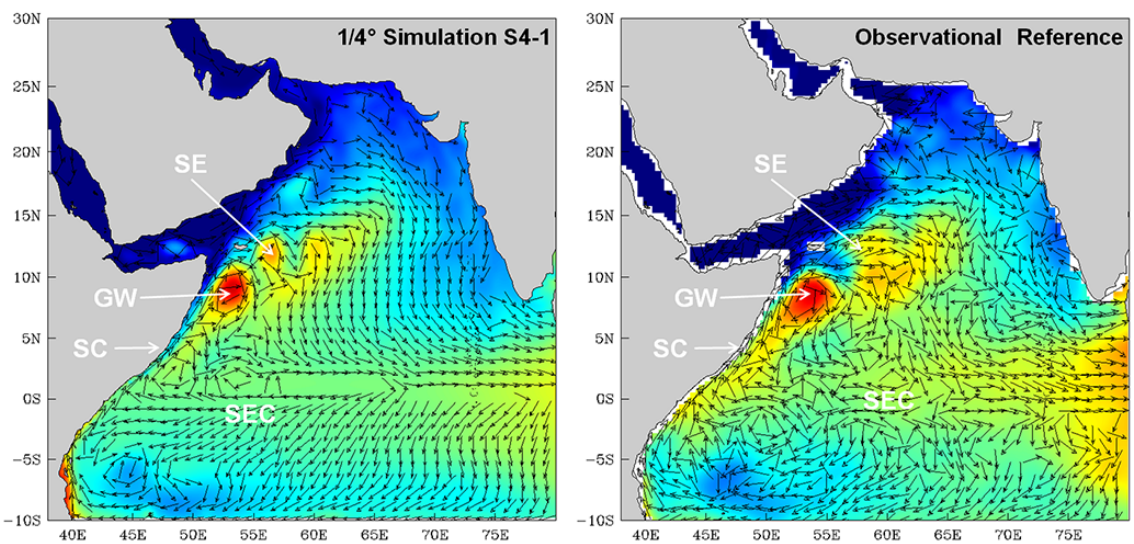

(b) Monthly mean - September

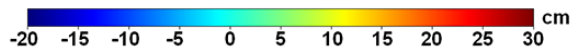

Figure 1. Climatological mean of the sea surface height (colour shading; $\mathrm{cm}$ ) with currents at $15 \mathrm{~m}$ depth superimposed (vectors; $\mathrm{m} \mathrm{s}^{-1}$ ) in the 1/4 $\mathrm{S} 4-1$ simulation and in the observational reference for: (a) the month of June and (b) the month of September. The model climatological mean is calculated over the last 10 years of the simulation. Currents smaller than $0.05 \mathrm{~m} \mathrm{~s}^{-1}$ are not plotted. SC is Somali Current. EACC is East African Coastal Current. SEC is South Equatorial Current. SECC is South Equatorial Counter Current. GW is Great Whirl. SG is Southern Gyre. SE is Socotra Eddy.

regional numerical model study of Vic et al. (2014) of the Arabian Sea points out the importance of the regional wind stress curl in the growth and maintenance of the GW, and the influence of basin-scale Rossby waves in its generation and its interannual variability.

Investigating the time evolution of these large eddies is possible since satellite altimeter measurements provide a dense enough mapping of the sea surface height (SSH). The analysis of 18 years of weekly AVISO SSH fields by Beal and Donohue (2013) revealed a chaotic evolution of the $\mathrm{GW}$, variations in size, shape and location of the eddy being greatly influenced by strong eddy-eddy interactions. Such behaviour was suggested by the idealized numerical model studies of Jensen (1991) and Wirth et al. (2002). This contrasts with the previous studies which convey the view of a $\mathrm{GW}$ that is slowly varying in response to the wind forcing (e.g. Schott and McCreary, 2001). Beal and Donohue (2013) observed that one to three cyclonic eddies of smaller size flank the GW most of the time, appearing in late June and circulating clockwise around the GW. They also observed the Socotra Eddy, but found that its variability in shape, size, and position was even greater than the one seen for the GW, making the SE often difficult to identify. Nevertheless, they report its frequent merging with the GW. At the best of our knowledge there is still no clear formation mechanism proposed for this eddy. The analysis of Beal and Donohue (2013) does not report any interaction between the SG and the GW, possibly because they limited the domain of study to $3-15^{\circ} \mathrm{N}$. However, the northward migration of the SG and its possible merging with the GW is mentioned in several observational studies (Evans and Brown, 1981; Swallow et al., 1983). Based on the observation of a merging of the southern cold 
wedge with the northern one, those studies suggest that the SG and the GW could coalesce. Such merging was also observed in the numerical model study of Luther and O'Brien (1989), but was not reported in the observations collected during the WOCE cruises of 1995-1996 (Schott et al., 1997).

The lack of understanding of the processes governing the dynamics of the large circulation features that are the SG, the $\mathrm{GW}$, and the Socotra Eddy largely resides in the lack of dense in space and time observations. The objective of the present study is to gain insights into the nature of the interactions between these anticyclonic eddies. The paper addresses the following questions:

- What is the generating mechanism of the cyclones flanking the GW?

- What is the nature of the interactions between the SG and the GW, and does the merging of the southern and northern cold wedges necessarily implies a coalescence of the two eddies?

- What is the formation mechanism of the Socotra Eddy?

We address the above questions through realistic numerical eddying model simulations, since they can provide dense spatio-temporal information required for a synoptic description of the mesoscale circulation.

The numerical model experiments that are the basis of our analysis are described in Sect. 2. The ability of the model to reproduce the upper-layer circulation in the Arabian Sea during the summer monsoon is assessed in Sect. 3. In Sect. 4 we perform a description and an analysis of the dynamics of the Somali Current eddies as simulated by the model experiments. In Sect. 5 we discuss the results put forward by our analysis of the eddy-eddy interactions in the western Arabian Sea and summarize the main findings.

\section{Numerical model simulations}

Three global ocean hindcast simulations, one at $1 / 4^{\circ}$ resolution and two at $1 / 12^{\circ}$ resolution, made available by the DRAKKAR consortium (DRAKKAR-Group et al., 2007, 2014) are used here to study the Somali eddies during the Southwest Monsoon.

The model configurations used to produce these hindcasts are based on the NEMO ocean/sea-ice general circulation numerical model (Madec, 2008) and utilize specifications developed by the DRAKKAR consortium. Among them is the ORCA025 eddy-permitting configuration which has a nominal resolution at the Equator of $0.25^{\circ}$ and 75 vertical levels. ORCA025 is extensively described in Barnier et al. (2006) and has been widely used to address scientific questions in physical oceanography, biogeochemistry, and marine biology (see refereed publications at www.drakkar-ocean.eu). Although ORCA025 is only eddy-permitting, even at these low latitudes, it is widely used to perform ocean reanalyses
(Balmaseda et al., 2015) and is the ocean component of several Earth System Models in Europe (Megann et al., 2014; Williams et al., 2015). Therefore, we find it useful to report any assessment of its solution. As is shown in this study, the eddy-permitting $1 / 4^{\circ}$ solution behaves in a way that is qualitatively comparable to the eddy-resolving $1 / 12^{\circ}$ solution in term of large-scale circulation of the Indian Ocean and in its representation of the main features of the Somali Current eddies.

The other model configuration is the ORCA12 eddyresolving configuration with a resolution of $1 / 12^{\circ}$ and 46 vertical levels. ORCA12 is the most recent and the highest-resolution global configuration of the DRAKKAR hierarchy, and its effective horizontal resolution ranges between $9.25 \mathrm{~km}$ at the Equator, $7 \mathrm{~km}$ at Cape Hatteras (midlatitudes), and $1.8 \mathrm{~km}$ in the Ross and Weddell seas. Models of that resolution have been shown to drastically improve the representation of western boundary currents (Maltrud and McClean, 2005; Maze et al., 2013). Driven by atmospheric forcing derived from atmospheric reanalysis (Brodeau et al., 2010), ORCA12 simulations are good tools to investigate global dynamical and thermo-dynamical balances (Deshayes et al., 2013; Treguier et al., 2014).

The specificities of the three simulations used here are presented in Table 1. Main differences between the simulations lie: in the horizontal resolution $\left(1 / 4^{\circ}\right.$ or $\left.1 / 12^{\circ}\right)$; or in the vertical resolution (75 or 46 levels); or in the atmospheric forcing used which can be ERA-interim (Dee et al., 2011) or the DFS4.3 atmospheric forcing (building on ERA40, Brodeau et al., 2010); or in the length of integration which can vary from 15 to 30 years; or in the side wall boundary conditions which can be free slip or partial slip. The differences in lateral friction (free-slip versus partial-slip boundary conditions) may have an impact on the mean profile of the boundary current, and consequently an impact on its stability. However, there are too many differences between the free-slip and the partial-slip experiments (differences in spin-up time, forcing, and period of integration, see Table 1) to assess in a significant manner the impact of the friction parameter on the eddy-eddy interactions described here.

The above discussion of the lateral friction parameter introduces our strategy of using those three different simulations. These global simulations were not initially designed to be sensitivity studies of the Arabian Sea to various processes or parameters - as were the regional simulations of Vic et al. (2014) for example - and are not suited to be used for such purpose. The use of several simulations rather than a single one is motivated by the fact that the solutions provided by present state-of-the-art eddy-resolving OGCMs still show some dependency on parameter choices and are subject to a chaotic behaviour specific to turbulent flows (Serazin et al., 2015). Identifying parts of the solution that are robust through all simulations contributes to building confidence in the results. A similar paradigm was used in the past for model inter-comparison studies (e.g. Willebrand et al., 2001; Bön- 
ing et al., 2001; Barnier et al., 2001). In the present case, because the focus is on highly non-linear turbulent processes, many occurrences of these processes are necessary to assess their significance. This is why we have chosen three simulations, each providing 10 years of data, such that in total 30 realizations of the SG/GW annual interaction cycle are available, from which scenarios are drawn.

The analysis of model results presented here is performed on the last 10 years of every simulation using model output every 5 days and focuses on features that are robust through all simulations. Because the model output provides a dense space and time sampling of the ocean variables, the tracking of the Somali Current eddies described here (mainly the GW and the SG) was simply made by looking carefully at individual snapshots.

\section{Arabian Sea upper-ocean circulation during the summer monsoon}

The ability of the above model configurations to realistically simulate the large-scale and mesoscale features of the global ocean circulation has been demonstrated in several studies (as mentioned in the previous section). We present here a short validation of the surface ocean circulation in the Arabian Sea during the Southwest Monsoon for the $1 / 4^{\circ}$ resolution ORCA025 simulation S4-1. The two ORCA12 simulations (S12-1 and S12-2) have been validated in the same way. The results described in this section, although illustrated with ORCA025, hold for the two ORCA12 simulations (small differences being the appearance of structures of smaller scale and some spatial and temporal lags expected from the turbulent nature of the flow), and are very consistent with the circulation schemes proposed in the literature (e.g. Schott et al., 2009; Beal et al., 2013). A more thorough validation of the $1 / 12^{\circ}$ model simulations can be found in Akuetevi (2014).

The model surface circulation during the summer monsoon is compared with an observational reference in Fig. 1. The climatological monthly means of the sea surface height (SSH) and of the currents at $15 \mathrm{~m}$ depth are displayed for June and September. Following what was done in Beal et al. (2013), the observational reference for the SSH is a combination of the AVISO sea level anomalies (SLA) data with the annual climatological mean SSH of Maximenko and Niiler (2005). The observational currents are the drifterderived currents from Lumpkin and Johnson (2013) which are a good proxy of the $15 \mathrm{~m}$ depth currents. The agreement between the model and the observations is qualitatively good. Drifter-derived currents are not as smooth as model currents (as expected due to their respective processing). Ekman currents are quite important at this depth, masking in some places the surface signature of the geostrophic currents.

In the early phase of the monsoon, both the model and the observations exhibit large similarities in their representation of the large-scale circulation patterns (June, Fig. 1a). The
EACC is well established as a northward continuous coastal current that stretches across the Equator from $10^{\circ} \mathrm{S}$ to $2^{\circ} \mathrm{N}$. A large part of the current turns offshore at around $2^{\circ} \mathrm{N}$ to form the SG, a retroflection loop that crosses back the Equator and joins the eastward flow of the SECC at about $4^{\circ} \mathrm{S}$. Note that the surface ( $15 \mathrm{~m}$ depth) signature of the SECC, the core of which is at $100 \mathrm{~m}$ depth, is weak and partly masked by the Ekman currents. Part of the EACC continues flowing northward along the coast and joins the $\mathrm{SC}$ at $3^{\circ} \mathrm{N}$. The SC flows along the coast of Somalia up to $10-12^{\circ} \mathrm{N}$ where it loops offshore to join an intense Great Whirl easily identified in Fig. 1a and $b$ by the strong SSH high off the Horn of Africa at $6-11^{\circ} \mathrm{N}$. The SC continues to flow northward beyond the GW, a branch passing through the Socotra Passage as described in Fischer et al. (1996) and Fratantoni et al. (2006), and another branch flowing around the Socotra Island by the east as reported in Schott and McCreary (2001) and Beal et al. (2013). Both branches join again north of the island to cross the mouth of the Gulf of Aden and flow north along the Omani coast.

Great similarities are also found between the model and observations in the late phase of the Southwest Monsoon (September, Fig. 1b). The EACC is fully connected with the $\mathrm{SC}$ to the point that it is not possible to distinguish between each current. The GW, identified by the SSH high off Somalia, has grown considerably. A relative SSH high (anticyclonic circulation) is observed to the northeast of the GW (and east of the Socotra Island) - it is the Socotra Eddy (SE) which forms at the end of July or at the beginning of August. The intensity of the GW and the SE begins to decrease in September, and both eddies disappear completely in November (not shown). The SG persists until the end of December (not shown).

At the scale of the whole Indian Ocean, the year-round large circulation patterns and the planetary wave dynamics (not shown, Akuetevi, 2014) simulated by the $1 / 4^{\circ}$ and $1 / 12^{\circ}$ models are in qualitatively good agreement with the analysis of surface drifter and satellite altimetry performed by Beal et al. (2013).

\section{Eddy dynamics along the Somali coast}

\subsection{Method}

In an attempt to answer the questions identified in the introduction, several quantities are diagnosed from the model 5-day outputs (Fig. 2). We compute the relative vorticity ( $\zeta$, Fig. 2a) to characterize the dynamical aspect of eddies, and use the sea surface temperature (SST, Fig. 2c) to detect the cold wedges.

We compute the spiciness ( $\Pi$, Fig. $2 b$ ) using the formula described in Flament (2002) on isopycnal $\sigma_{0}=23.8$ (the depth of which varies between 50 and $100 \mathrm{~m}$ ). Spiciness quantifies whether waters on a given isopycnal are warm and 
Table 1. Specificities of the global model simulations. Only differences between runs are reported. The full model characteristics are described in Drakkar technical reports by Lecointre et al. (2011a, b) and are summarized in DRAKKAR-Group et al. (2014). Model variables are stored every 5 days as 5-day means.

\begin{tabular}{llll}
\hline DRAKKAR Simulation reference & ORCA025.L75-MJM95 & ORCA12.L46-MAL84 & ORCA12.L46-MAL95 \\
Reference in the paper & S4-1 & S12-2 & S12-1 \\
\hline Horizontal resolution & $1 / 4^{\circ}$ & $1 / 12^{\circ}$ & $1 / 12^{\circ}$ \\
Vertical level (with partial steps) & 75 & 46 & 46 \\
Lateral boundary condition & free slip & free slip & partial slip \\
Initial conditions & From rest, Levitus (1994) & From rest, Levitus (1994) & 10 years spin-up (1978-1988) with CORE forcing \\
& & & (Large and Yeager, 2009) \\
Atmospheric forcing & ERAinterim & DFS4.3 & ERAinterim \\
Starting date & 1 January 1989 & 1 January 1978 & 1 January 1989 \\
Ending date & 31 December 2009 & 31 December 1992 & 31 December 2007 \\
Duration & 21 years & 15 years & 30 years \\
\hline
\end{tabular}

(a) Relative vorticity

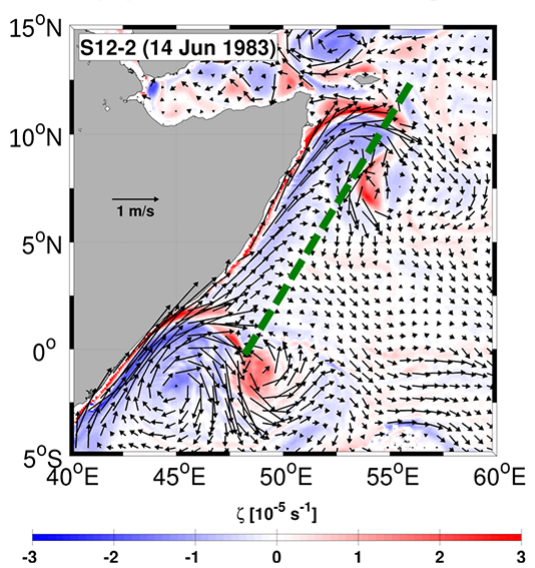

(c) Surface temperature

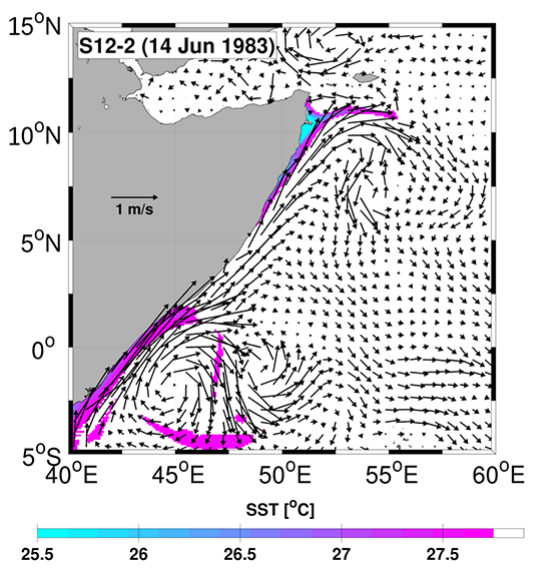

(b) Spiciness

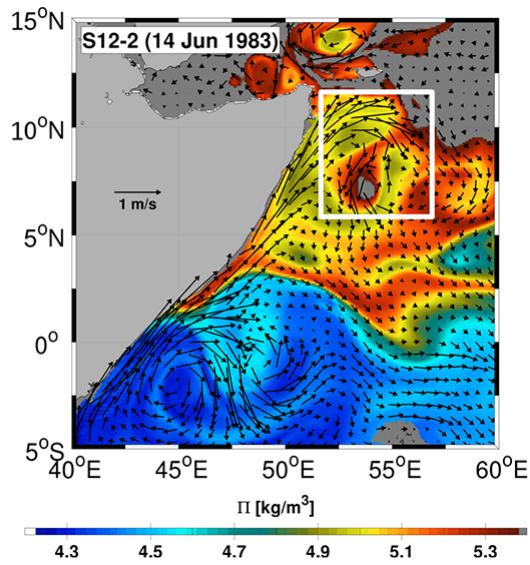

(d) Vertical section

Figure 2. Top panels: snapshot (on 14 June 1984 from the $1 / 12^{\circ} \mathrm{S} 12-2$ experiment) of surface currents (vectors; $\mathrm{m} \mathrm{s}^{-1}$ ) superimposed on (a) the relative vorticity $\left(\zeta\right.$; colour shading; $\mathrm{s}^{-1}$ ) at depth $50 \mathrm{~m}$; (b) the spiciness on $\sigma_{0}=23.8\left(\Pi\right.$; colour shading; $\mathrm{kg} \mathrm{m}^{-3}$ ). The square box (white line) is the GW box which defines the area where statistics of spiciness have been calculated. Bottom panels: (c) snapshot of the sea surface temperature (SST; colour shading; ${ }^{\circ} \mathrm{C}$ ); (d) this panel shows along an oblique section parallel to the coast (and passing through the Somali eddies as shown on the relative vorticity panel): the depths of the isopycnals comprised in the range $22 \leq \sigma_{0} \leq 26.4$ (black contours by interval of 0.2 ), the variation of relative vorticity $\zeta$ at $50 \mathrm{~m}$ depth (green line), and the variation of the current speed $U$ at depth $50 \mathrm{~m}$ (blue line). 
salty (i.e. "spicy" with large values of $\Pi$ ) or cold and fresh (i.e. "minty" with low values of $\Pi$ ). Because this quantity is conserved on isopycnal surfaces in the absence of mixing and surface fluxes (Flament, 2002), it is used here as a tracer characterizing the water masses transported by eddies, or to assess mixing occurring along stream of a given current. It is particularly interesting here because it allows us to distinguish between the minty waters of Southern Hemisphere origin that characterize the SG and the spicy waters of the North Indian Ocean that characterize the GW as illustrated in Fig. 2b. The velocity field (vectors) at the depth of $50 \mathrm{~m}$ is superimposed on the above quantities to visualize currents and eddies. To access the vertical structure of eddies, we compute the depths of the isopycnals comprised in the range $22 \leq \sigma_{0} \leq 26.4$ along a section parallel to the coast passing through the core of the large eddies (green line in Fig. 2a). These isopycnals (Fig. 2d) spread over the first $250 \mathrm{~m}$ and capture well the vertical eddy shape. The current speed and the relative vorticity at $50 \mathrm{~m}$ depth along the section are superimposed. Note that the position of the SG and the GW at mid-June (Fig. 2) will be considered as a starting position to access the dynamics of these anticyclones in Sect. 4.3.

\subsection{Small cyclonic eddies}

This section focuses on the dynamic that goes along with the seasonal growth and evolution of the GW and the SG. It relies on the analysis of the 5-day snapshots of relative vorticity $(\zeta)$ and current fields.

\subsubsection{Bursts}

During the northward migration of the SG in June and early July, detachments of positive vorticity from the western boundary current (WBC) are observed in all three experiments (e.g. Figs. 3, 4, and 7) around the SG and the GW. These detachments are the intense phenomena exhibiting the strongest velocity and vorticity gradients. Their vertical structure reaches beyond the thermocline depth (not shown). In the three experiments, there is a thin sheet of positive vorticity that stretches along the western boundary (at the inner side of the SC and the EACC on every plot of Fig. 3). This sheet results from the lateral shear of the SC whose circulation is intensified by the growth of the GW. Entrained by the swirling motion of the large anticyclones, this filament of positive vorticity is torn off the boundary and moves toward the open ocean (see Fig. 3). North of the detachment, the positive vorticity anomaly of the boundary current vanishes. These events were previously identified and called bursts in analogy with the bursts or ejections of vorticity patterns in the classical western boundary-layer dynamics (see Robinson, 1991; Akuetevi and Wirth, 2015). Akuetevi and Wirth (2015) explain that the thin layer of large positive values (cyclonic) of relative vorticity that exists along the coast in a low-latitude western boundary current is the siege of intermittent detachments of such cyclonic vorticity bursts. Note that if the occurrence of the bursts compares well between all simulations, the ejection of the bursts off the boundary and their offshore motion are much better resolved at $1 / 12^{\circ}$ than at $1 / 4^{\circ}$ resolution, as can be seen in Fig. 3 .

\subsubsection{Dipoles}

The positive vorticity anomalies ejected from the boundary during the bursts spin cyclonically and generate coherent cyclonic eddies, the vertical extent of which can reach beyond $300 \mathrm{~m}$ depth (not shown). These cyclones often pair with the negative vorticity within the large anticyclones to form asymmetric dipoles (Fig. 3). We suggest that these cyclones are the model analogues of the "flanking cyclones" of the GW evidenced by Beal and Donohue (2013) in their analysis of satellite altimeter data. The behaviour of the asymmetric dipole appears to be influenced by the trajectory of the small cyclonic vortex. Two different scenarios were observed in our simulations.

i. The cyclonic vortex remains attached to the large anticyclonic eddy, circles around it, and returns towards the western boundary before being sucked up into the large anticyclonic eddy in a merging event.

This is illustrated in Fig. $3 b$ for the $1 / 12^{\circ}$ simulation: on 19 June (middle-right panel), the cyclone is located in the centre of the GW (the red spot outlined by the green arrow). On 9 July (bottom-right panel), the cyclone has greatly diminished its intensity and is being absorbed into the GW. It is possible that this process weakens the large anticyclonic eddy and contributes to its decay. The cyclonic vortices created by the GW most often follow this trajectory. This trajectory is the one proposed by the analysis of Beal and Donohue (2013).

ii. The cyclonic vortex does not pair with large anticyclonic eddy and drifts in the open ocean.

This is illustrated in Fig. 7a where most cyclones located east of $55^{\circ} \mathrm{E}$ (outlined by the purple and green circles) will not reenter the boundary current system and will remain offshore.

The behaviour of the bursts after ejection followed by the dipoles formation is a very well-marked phenomenon which entrains the upwelled-water masses detached by the bursts from the cold wedge and could contribute to their offshore mixing. The properties of the water masses transported by the SG and the GW are changing during the course of the Southwest Monsoon (Figs. 5 and 6). The bursts, their transformation into cyclonic eddies and their chaotic behaviour contribute to entrain upwelled waters within the eddies and offshore the Somali Coast.

The dynamics of the bursts also injects positive vorticity within the large anticyclonic seasonal eddies (the SG and the 

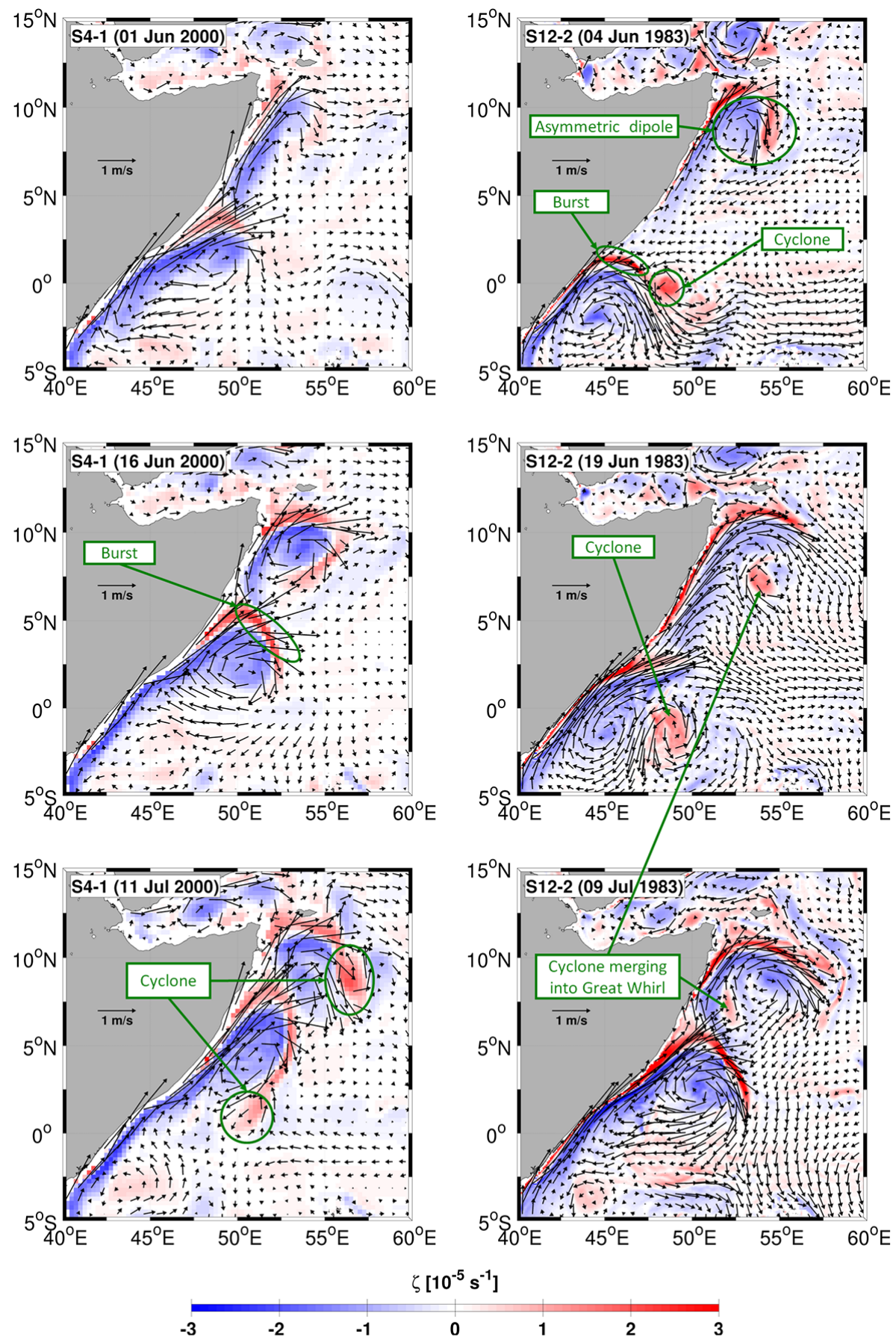

(a) $1 / 4^{\circ}$ simulation $\mathrm{S} 4-1$

(b) $1 / 12^{\circ}$ simulation $\mathrm{S} 12-2$

Figure 3. Sequence of relative vorticity ( $\zeta$; colour shading; $\mathrm{s}^{-1}$ ) and currents (vectors; $\mathrm{m} \mathrm{s}^{-1}$ ) at $50 \mathrm{~m}$, (a) in the $1 / 4^{\circ} \mathrm{S} 4-1$ simulation, and (b) in the $1 / 12^{\circ} \mathrm{S} 12-2$ simulation. The sequences show the occurrence of the vorticity bursts and their subsequent development into asymmetric dipoles. The two large pools of negative (blue) vorticity are the SG and the GW. The bursts are the filaments of positive (red) vorticity, and the cyclones are the circular features of positive (red) vorticity. 

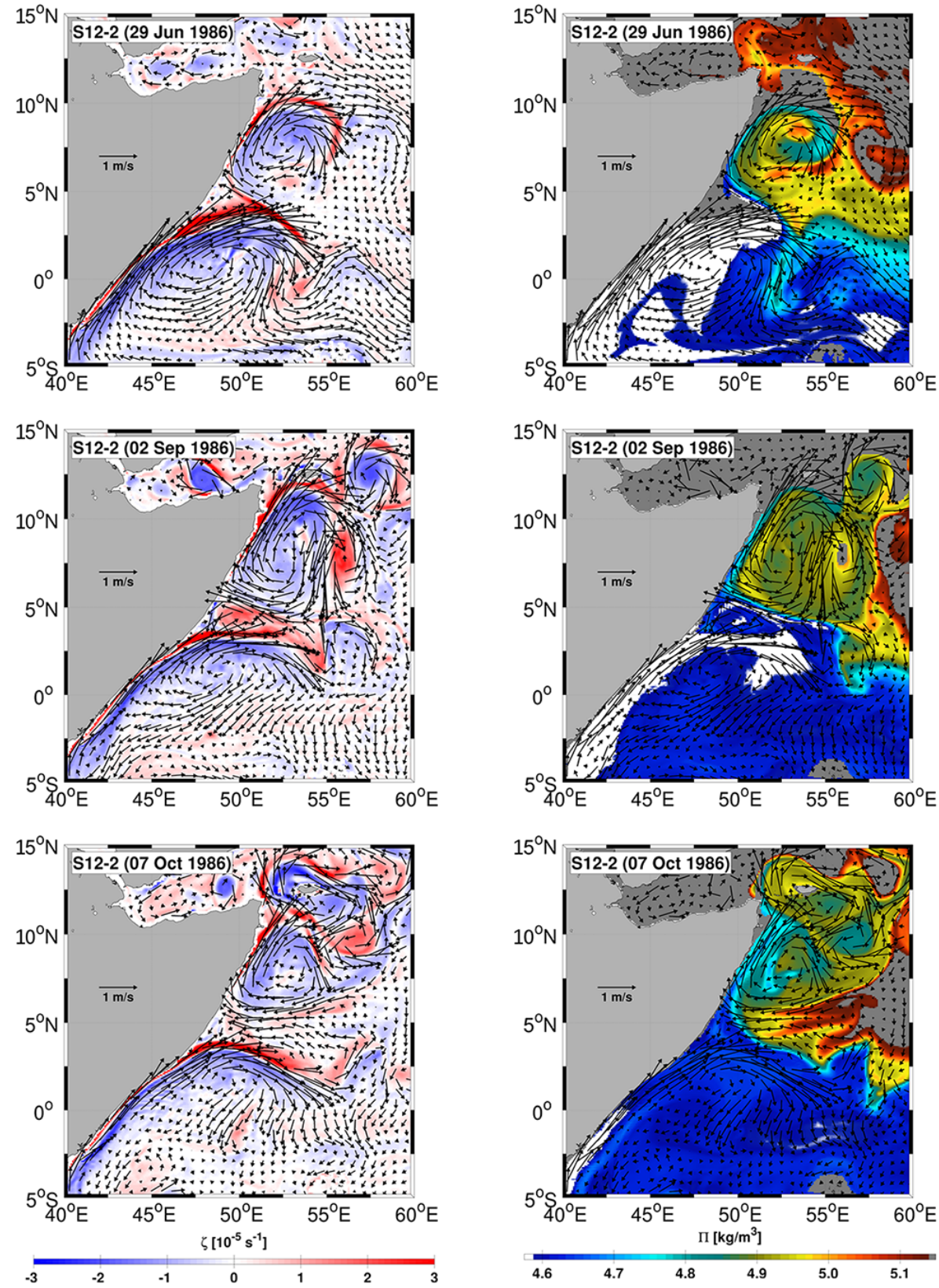

(a) Relative vorticity

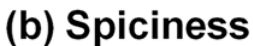

Figure 4. Snapshots of current (vectors; $\mathrm{m} \mathrm{s}^{-1}$ ) at $50 \mathrm{~m}$ superimposed on (a) relative vorticity ( $\zeta$; colour shading; $\mathrm{s}^{-1}$ ) at $50 \mathrm{~m}$ and $(\mathbf{b})$ spiciness on isopycnal $\sigma_{0}=23.8$ ( $\Pi$; colour shading; $\mathrm{kg} \mathrm{m}^{-3}$ ), at three different stages of the Southwest Monsoon in 1986 in the $1 / 12^{\circ} \mathrm{S} 12$ 2 simulation.

$\mathrm{GW}$ ), prompting the short-timescale variability of these eddies, as observed by Beal and Donohue (2013), but also contributing to their decay.

Note that if the dynamics of bursts and the development of dipoles are clear and well marked in the simulations at $1 / 12^{\circ}$ (ORCA12), they are more diffused although noticeable at $1 / 4^{\circ}$ resolution, suggesting that this latter resolution permits the generation of the process but not its full development.

\subsection{Large anticyclones}

To unravel the dynamical interactions between the large Somali eddies we use the 5-day outputs of the $1 / 12^{\circ} \mathrm{S} 12-2$ and S12-1 experiments since we have shown that the eddy dy- 
namics is better resolved than in the $1 / 4^{\circ}$ experiment. But what is described hereafter is generally valid for the $1 / 4^{\circ}$ simulation.

\subsubsection{Interaction between the Southern Gyre and the Great Whirl}

At the beginning of June (4 June in Fig. 3 right panel), the GW spins up between 6 and $10^{\circ} \mathrm{N}$ while the SG still stretches across the Equator. The intensification of the Southwest Monsoon during June (19 June in Fig. 3) amplifies the intensity of the GW (which nevertheless exhibits a shortterm variability in position and shape due to the burst dynamics). Simultaneously the EACC strengthens and the SG begins a northward migration at a speed of approximately $1 \mathrm{~m} \mathrm{~s}^{-1}$, migration that usually brings it in contact with the GW around mid-July (Fig. 3, 9 July). Then different scenarios are seen.

i. The SG stops its migration and remains at its location south of $5^{\circ} \mathrm{N}$ during the whole monsoon period (Fig. 4). The GW also remains at its original location. A SE is seen east of Socotra Island. This is the scenario reported in most schematics of the circulation of the western Arabian Sea. The evolution of the two eddies is then dominated by their chaotic interactions with the cyclonic bursts until their dislocation when the Southwest Monsoon winds vanish. This scenario is not frequent but it is common to all simulations.

ii. The SG collides with the GW but the two eddies do not merge (Fig. 5). The GW is pushed to the northeast and its size is significantly reduced due to its interaction with the topography of the Socotra Island. The interaction of the GW with the island is very chaotic. The GW often sheds patches of anticyclonic vorticity of smaller size that circulate around the island, sometimes passing through the Socotra Passage before entering in the Gulf of Aden. However, the core of the GW most of the time becomes a smaller but intense eddy located at the east/southeast of the Socotra Island, commonly called the Socotra Eddy (SE). The migrated SG takes the place of the GW. This scenario is the most frequent and is robust through the simulations since it occurred 22 times over the 30 years covered by the three simulations altogether (nearly $75 \%$ of the cases). This process is discussed in detail in Sect. 4.3.2. On rare occasions, the GW is pushed through the Socotra Passage (Fig. 6) and forms an anticyclonic vortex translating slowly into the Gulf of Aden. Note that the SST plots of Fig. 5 show a coalescence of the two cold wedges.

iii. On rare occasions the SG absorbs part of the GW during the collision process (Fig. 7). But this only occurred twice in the $1 / 12^{\circ} \mathrm{S} 12-1$ simulation which used a partial slip boundary condition. The robustness of this "merg- ing scenario" regarding the model parameters is therefore not established and it must be considered with caution.

The three simulations, despite their differences in grid resolution or parametrization, show that the formation and the behaviour of the large Somali anticyclones follow these scenarios, which emphasizes the chaotic dynamics of the Somali anticyclones and motivates a more detailed description of the collision process.

\subsubsection{Collision}

This section addresses the question of the nature of the interaction between the SG and the GW. Some observations have suggested that the two eddies could at times collapse. This suggestion has been mainly based on the satellite observation of the rapid northward migration $\left(\sim 1 \mathrm{~m} \mathrm{~s}^{-1}\right)$ of the southern cold wedge and its collapse with the northern cold wedge (Evans and Brown, 1981). But as strongly suggested by our model results, the coalescence of the two cold wedges does not necessarily mean that the SG and the GW are merging.

A sequence of 5-day average snapshots of the S12-2 experiment during the Southwest Monsoon (July to September) in 1983 is shown in Fig. 5 to illustrate the collision (also the most frequent) scenario.

The initial condition of this sequence is described by the situation shown in Fig. 3b (period from 4 June to 9 July 1983 in S12-2) when the SG, initially located in the Southern Hemisphere and being well separated from the GW, rapidly migrates northward to encounter the GW at the beginning of July.

A few days later (14 July in Fig. 5), the cross-equatorial flow of the EACC extends up to $5^{\circ} \mathrm{N}$ where it turns offshore to form the northern edge of the SG which appears now as a closed anticyclonic circulation centred at about $3^{\circ} \mathrm{N}(\zeta$ plot), embedding low spiciness "minty" waters $(\Pi$ plot). On its northern flank the SG shows a wedge of cold upwelled water shooting offshore at about $6^{\circ} \mathrm{N}$ - the southern cold wedge (SST plot). At this moment, the GW is well established. It appears as a very coherent anticyclonic eddy centred at about $7^{\circ} \mathrm{N}$, squeezed between the SG to the south and the Socotra Island to the north and embedding waters of relatively high spiciness. North of it, the northern cold wedge (SST plot) stretches far offshore. The vertical section crossing the two eddies (Fig. 8) shows that they are separated by well-marked fronts in density, velocity, and relative vorticity.

Ten days later (24 July in Fig. 5), the SG continued its northward migration (its centre is now located at $5^{\circ} \mathrm{N}$ ). It is now colliding with the GW which begins to dislocate into vorticity patches of smaller size. The spiciness shows that no merging occurs since each core keeps its own spiciness characteristics.

Again 10 days later (3 August in Fig. 5), the SG is now located where the GW was before (its core is at about $7^{\circ} \mathrm{N}$ ). Although its spiciness has increased due to entrain- 

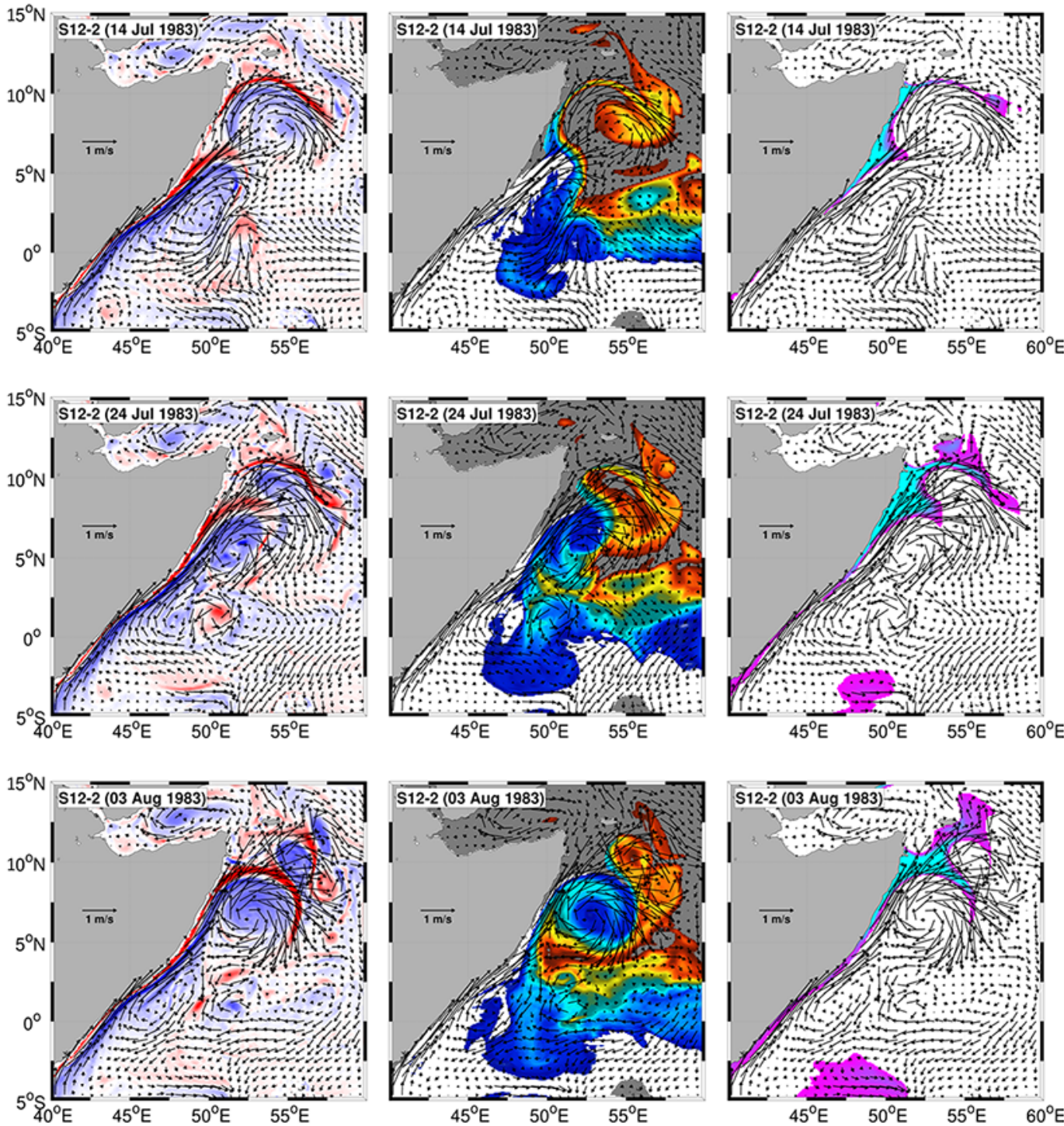

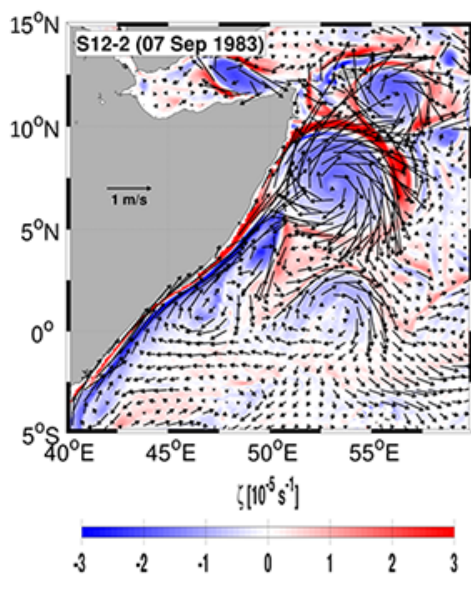

(a) Relative vorticity

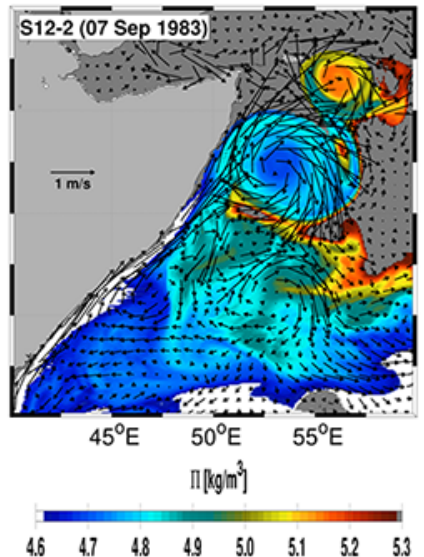

(b) Spiciness

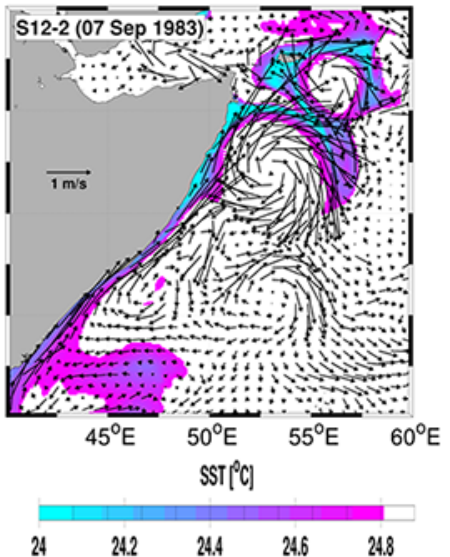

(c) Surface temperature

Figure 5. Sequence of snapshots describing the most frequent scenario during the well-established Southwest Monsoon period. Surface currents (vectors; $\mathrm{m} \mathrm{s}^{-1}$ ) are superimposed on (a) the relative vorticity ( $\zeta$; colour shading; $\mathrm{s}^{-1}$ ) at depth $50 \mathrm{~m}$, (b) the spiciness on $\sigma=23.8$ ( $\Pi$; colour shading; $\mathrm{kg} \mathrm{m}^{-3}$ ), and (c) the sea surface temperature (SST, colour shading, ${ }^{\circ} \mathrm{C}$ ). This sequence is from the $1 / 12^{\circ} \mathrm{S} 12-2$ simulation. 


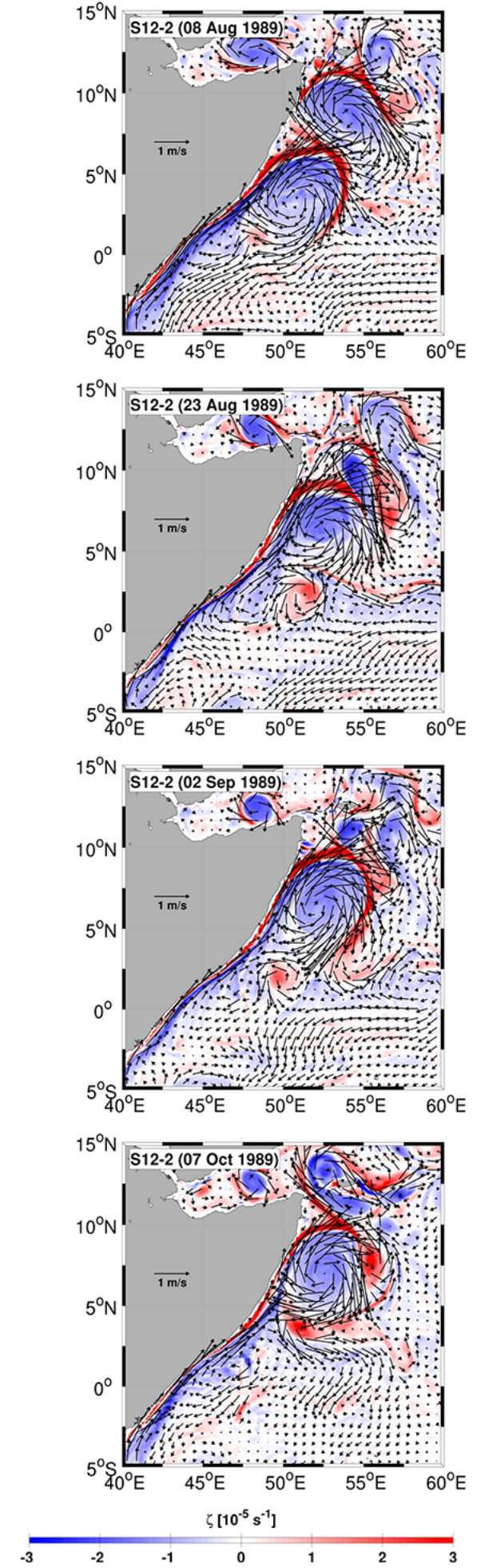

(a) Relative vorticity
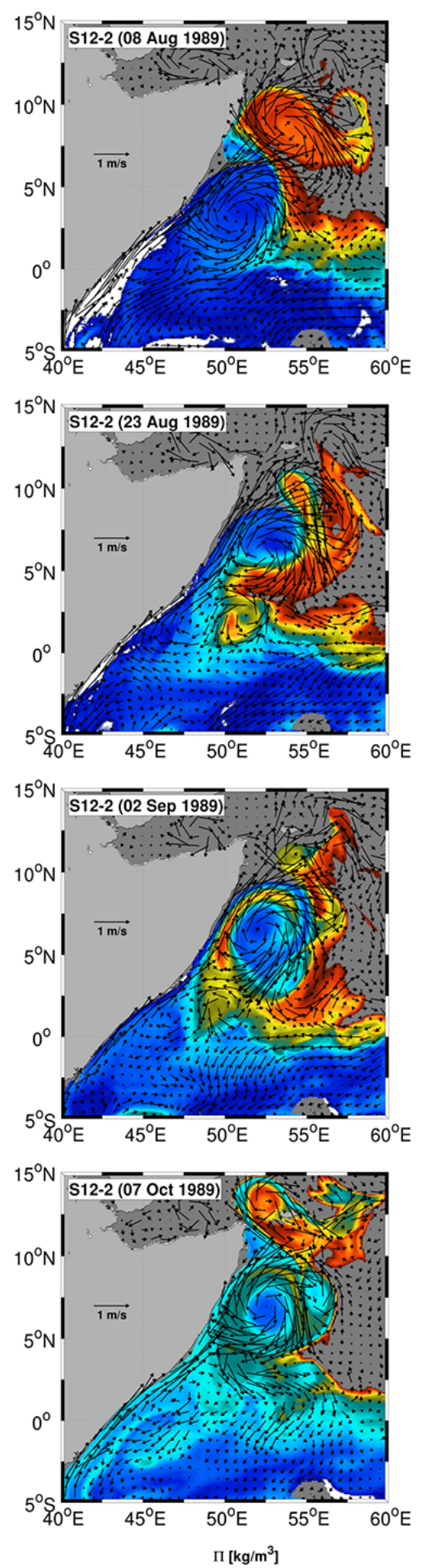

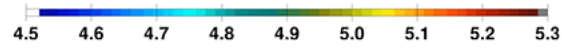

(b) Spiciness

Figure 6. Snapshots of current (vectors; $\mathrm{m} \mathrm{s}^{-1}$ ) at $50 \mathrm{~m}$ superimposed on (a) relative vorticity ( $\zeta$; colour shading; $\mathrm{s}^{-1}$ ) at $50 \mathrm{~m}$ and $(\mathbf{b}) \mathrm{spici-}$ ness on isopycnal $\sigma_{0}=23.8$ ( $\Pi$; colour shading; $\mathrm{kg} \mathrm{m}^{-3}$ ), between August and October 1989 in the $1 / 12^{\circ} \mathrm{S} 12-2$ simulation. 


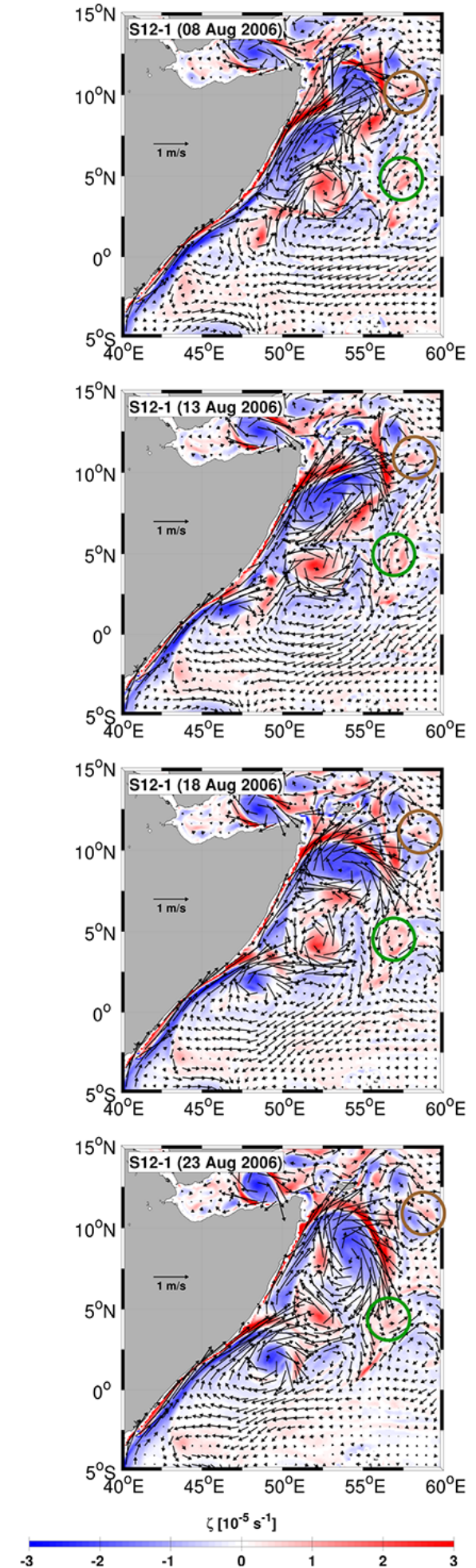

(a) Relative vorticity
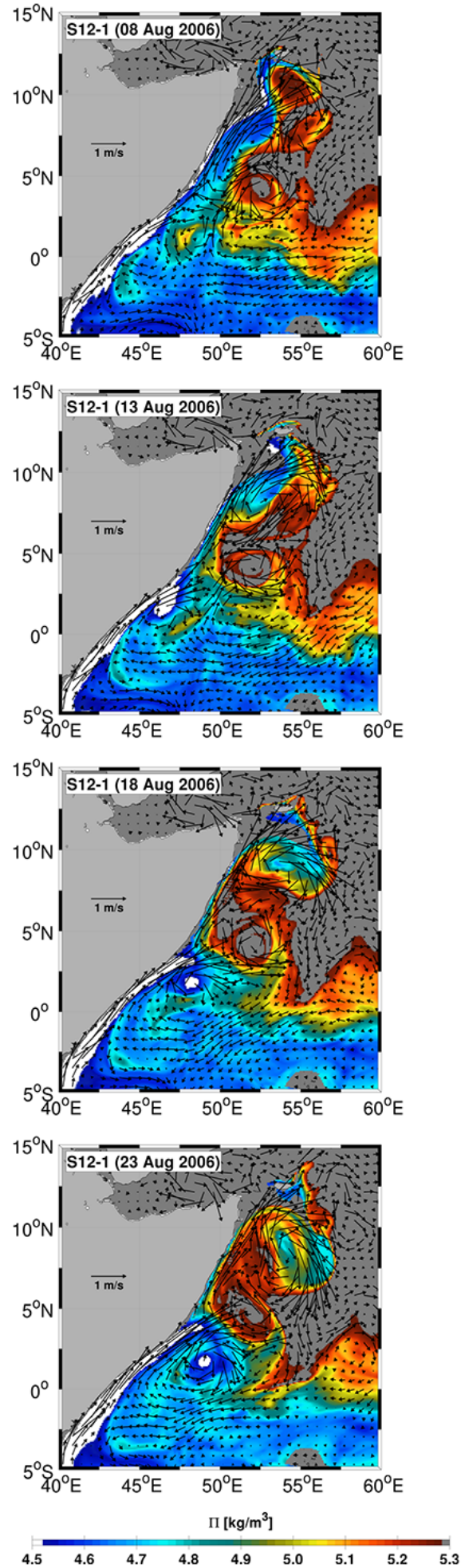

(b) Spiciness

Figure 7. Snapshots of current (vectors; $\mathrm{m} \mathrm{s}^{-1}$ ) at $50 \mathrm{~m}$ superimposed on (a) relative vorticity ( $\zeta$; colour shading; $\mathrm{s}^{-1}$ ) at $50 \mathrm{~m}$ and $(\mathbf{b}) \mathrm{spici-}$ ness on isopycnal $\sigma_{0}=23.8$ ( $\Pi$; colour shading; $\mathrm{kg} \mathrm{m}^{-3}$ ), between August and October in 2006 in the $1 / 12^{\circ} \mathrm{S} 12-1$ simulation. The green and brown circles outline cyclonic vortexes generated from bursts. 

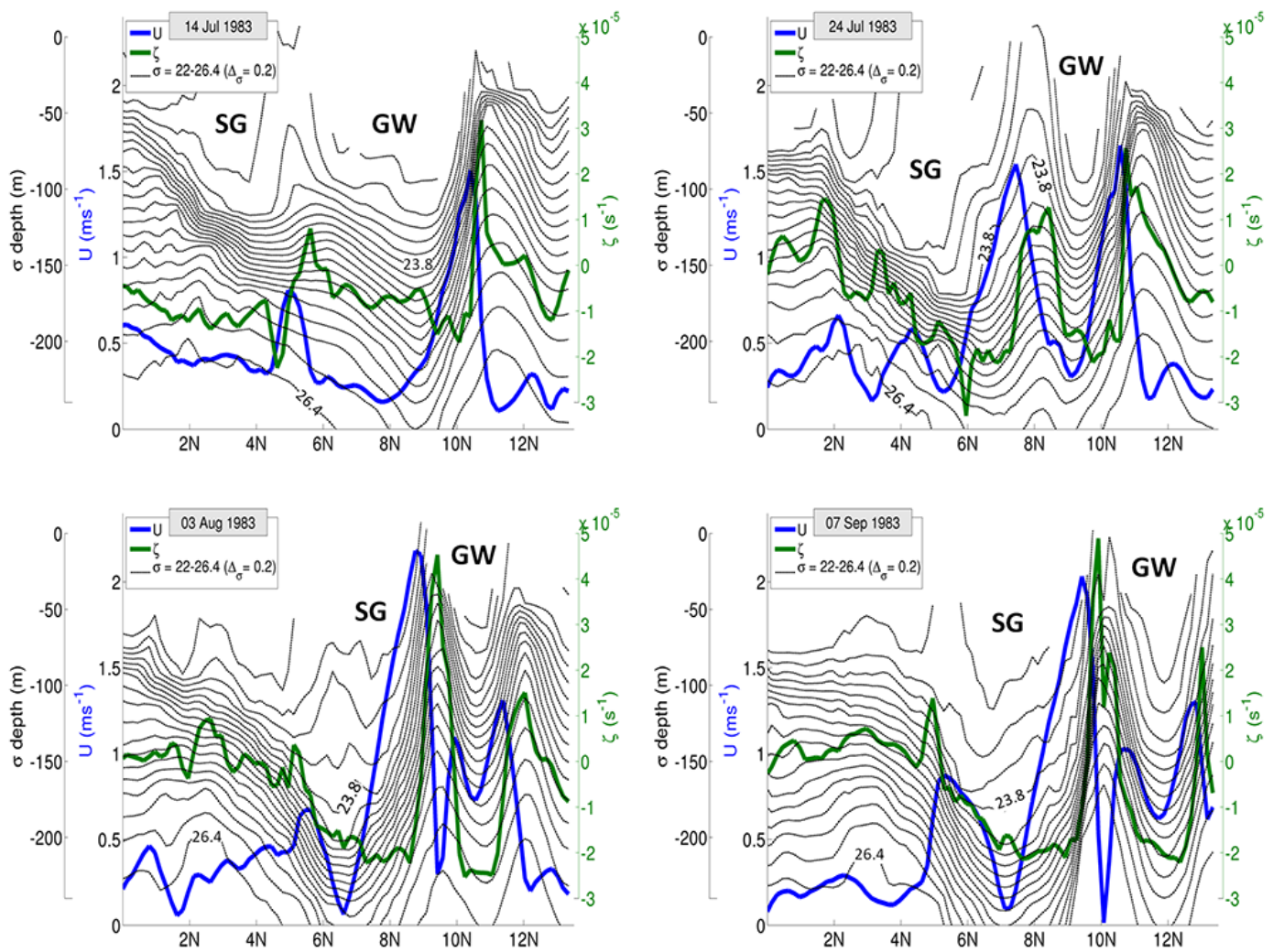

Figure 8. Sequence (corresponding to that of Fig. 5) along an oblique section parallel to the coast (and passing through the Somali eddies as shown on the relative vorticity panel) of: the depths of the isopycnals within the range $22 \leq \sigma_{0} \leq 26.4$ (black contours by interval of 0.2 ), the variation of relative vorticity $\zeta$ at $50 \mathrm{~m}$ depth (green curve), and the variation of the current speed $U$ at depth $50 \mathrm{~m}$ (blue curve).

ment and mixing with surrounding waters, it is still characterized by a core of low-spiciness waters. The GW has moved to the northwest, has significantly reduced in size and is still squeezed between the SG and Socotra Island. It still has a core of waters of relatively high spiciness. The front separating the two eddies has considerably increased its intensity. Figure 8 shows that from 24 July to 3 August the velocity of the front at $50 \mathrm{~m}$ depth has increased from 1.5 to above $2 \mathrm{~m} \mathrm{~s}^{-1}$, the vorticity from 1 to $4.5 \times 10^{-5} \mathrm{~s}^{-1}$, and the density change across the front has increased by $1.5 \mathrm{~kg} \mathrm{~m}^{-3}$. The strength of this "border" on the one hand and the stratification of the two eddies and their annuli of positive relative vorticity (that lead to a shielded relative vorticity structure) on the other hand are strong indications that the two eddies cannot merge (see Valcke and Verron, 1997). Note that the northern and southern cold wedges have merged.

A month later (7 September in Fig. 5), the SG has continued its northward move, has expanded in size with increased spiciness, and now occupies a place usually occupied by the GW. The GW, the spiciness of which has decreased, is pushed to the east of the Socotra Island to the position where the SE is usually observed. The fronts separating the two eddies are still very intense. Although the variations of spiciness (true also for temperature and salinity, not shown) of the SG and the GW during the interaction are noticeable, their spiciness differed persistently. This is consistent with the ship survey observations by Fischer et al. (1996) and Schott et al. (1997, their Fig. 1) who observed a difference in surface salinities between the GW and the SE at the end of August and early September.

The collision did not produce the coalescence between the SG and the GW, but their respective cold wedges have merged. It appears clearly from the simulations that the SE may emerge from the collision without merging between the SG and the GW. This collision generally takes place from mid-July to mid-August, but exhibits interannual variability.

However, the influence of the Socotra Island on the evolution of the GW during the collision process is very chaotic and does not always result in the generation of a well-defined Socotra Eddy. As shown in another sequence in 1989 (Fig. 6), the GW may dislocate during the collision and break into anticyclones of much smaller size, some remaining nearby the island and appearing as a non-well-formed SE of short lifetime, and some moving through the Socotra Channel into the Gulf of Aden. Therefore, rather than a well-defined coherent eddy, the SE should be seen as a patch of anticyclonic vorticity resulting from the interaction of the GW with the 
topography that is almost always present east of Socotra Island after the collision took place.

A merging scenario in which the SG absorbs a large part of the GW during the collision process has been seen to occur on two occasions but in the S12-1 simulation only (Fig. 7). This simulation uses a partial-slip boundary condition (others use free slip) which modifies the vorticity balance of the boundary current and is expected to have an impact on eddy/eddy and eddy/topography interactions. Indeed, the greatest differences between the S12-2 and S12-1 simulation (both at $1 / 12^{\circ}$ ) are seen in the way the GW dislocates in smaller vorticity patterns during its collision with the SG. Concerning the dynamics of the Somali Current eddies studied here, all simulations clearly favour the collision scenario (9/10 in S12-2, 8/10 in S4-1, and 7/10 in S12-1), differences being in details. The robustness of the "merging scenario" regarding the model parameters is therefore not established and it must be considered with caution. But one cannot rule out that such merging may occur in some years since we have no definite arguments to assess that one simulation is systematically better than the other.

To better understand the collision between the SG and the $\mathrm{GW}$, it is useful to analyse the evolution of their vertical profiles (Fig. 8) that correspond to the case of collision without merging of the sequence of Fig. 5. The vertical profiles show that when eddy-eddy interactions begin (plot of 14 July) the frontier separating the two eddies at about $5^{\circ} \mathrm{N}$ is characterized by a positive vorticity associated to a strong confined current $\left(0.8 \mathrm{~m} \mathrm{~s}^{-1}\right)$ and a marked density front. This suggests that the cores of the two eddies are separated by a vorticity shield of opposite sign, which makes their merging very unlikely (Valcke and Verron, 1997). As the collision process develops (plot of 3 August) the frontier (which is now between $8-10^{\circ} \mathrm{N}$ since both eddies have migrated northward) is considerably reinforced: the intensity of the positive vorticity barrier has been multiplied by 5 , the current is extremely intense $\left(>2 \mathrm{~m} \mathrm{~s}^{-1}\right)$ and the density front has also drastically intensified, making the merging even more unlikely.

\subsection{Evolution of spiciness in the Great Whirl region}

As mentioned before (e.g. in Sect. 4.1), the water masses found in the GW in its early stage (e.g. June) are characterized by a significantly higher spiciness $(\Pi)$ than that found in the SG. As illustrated in Fig. 2 (or in Fig. 12) for experiment $S 12-2$, typical $\Pi$ values in June range between 5.0 and 5.4 in the GW, and between 4.4 and 4.9 in the SG. We also found that the other $1 / 12^{\circ}$ experiment S12-1 is globally "spicier" than S12-2 such that typical $\Pi$ values range from 5.5 to 5.9 in the $\mathrm{GW}$, and from 4.7 to 5.2 in the $\mathrm{SG}$ (see Fig. 9). In this section we use these characteristics to look at the collision process of the two large anticyclones through the time evolution of the spiciness in the region where the GW is usually standing. This region is defined by the GW box, a $5^{\circ} \times 5^{\circ}$ box (4092 model grid points) located between
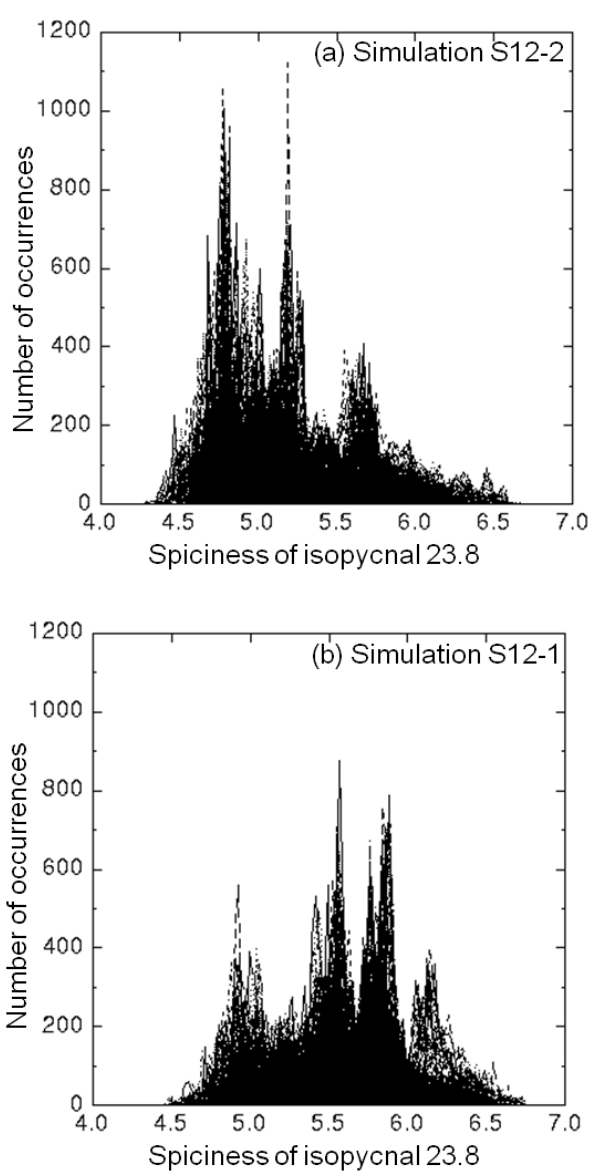

Figure 9. Histogram of spiciness ( $\Pi$ ) on isopycnal surface $\sigma_{0}=23.8$ in the GW box from 10 years of 5-day snapshots for the $1 / 12^{\circ}$ simulations: (a) S12-2 and (b) S12-1. The GW box (see text) includes 4092 model grid points. 200 bins of $0.015 \mathrm{~kg} \mathrm{~m}^{-3}$ between the values of 4 and $7 \mathrm{~kg} \mathrm{~m}^{-3}$ are used to construct the histograms. The peak around spiciness values of 6.2 in S12-1 is due to a single year (2006).

$\left(6.72-11.72^{\circ} \mathrm{N}\right.$ and $51.25-56.70^{\circ} \mathrm{E}$ ) (see Fig. 2). The collision without merging would show a rapid replacement of spicy waters by minty waters. Histograms of spiciness in the GW box calculated over the 10-year period of the simulations are shown in Fig. 9. These distributions exhibit very distinct peaks. The peak in the low values $(\Pi<5.0)$ means that there are periods of the year when waters of low spiciness are found in the area where the GW usually stands, which is consistent with the merging scenario.

The greater amplitude of this peak in S12-2 (compared to S12-1) is also consistent with tendency of S12-2 to be more favourable to the collision scenario.

However, the above histograms do not discriminate the seasons at which the various peaks occur. We therefore look at the time evolution of the PDF of the spiciness in the GW box. This PDF is calculated as the number of points in a given bin of spiciness divided by the width of the bin and 


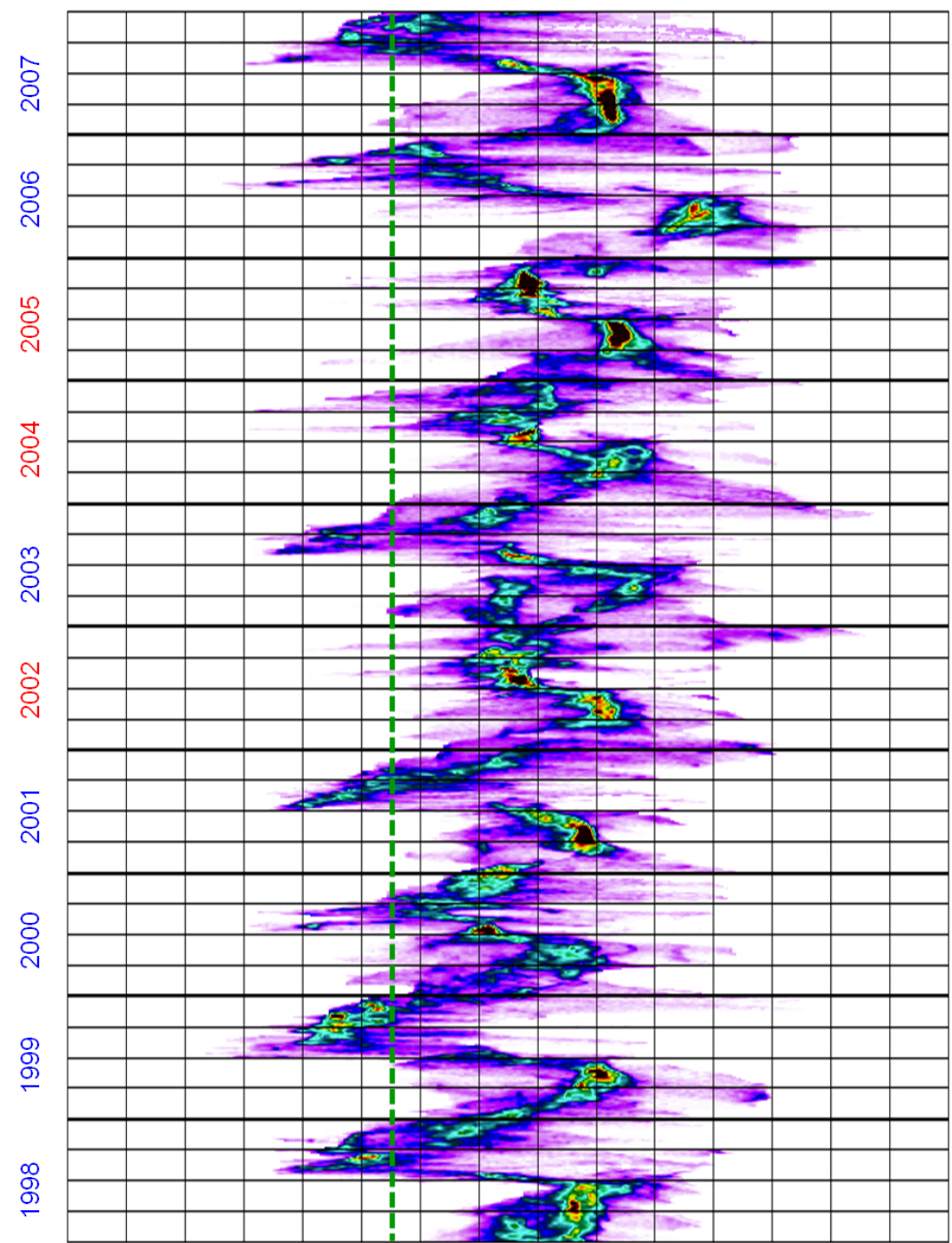

$\begin{array}{llllllllllllllllll}4.0 & 4.2 & 4.4 & 4.6 & 4.8 & 5.0 & 5.2 & 5.4 & 5.6 & 5.8 & 6.0 & 6.2 & 6.4 & 6.6 & 6.8 & 7.0\end{array}$ Spiciness $\left(\mathrm{kg} \cdot \mathrm{m}^{-3}\right)$

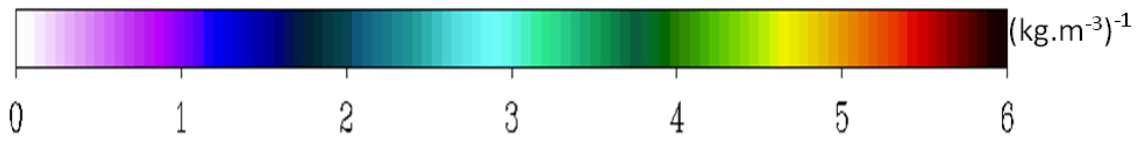

Figure 10. Evolution diagrams in the Spiciness versus Time space of the PDF of $\Pi$ (the spiciness on isopycnal 23.8) in the GW box (from simulation S12-1). All 5-day snapshots are shown. Colours indicate the values of the PDF. The green dashed line indicates the value of $\Pi$ below which the spiciness is considered as being characteristic of the SG waters. Years in blue are years of collision with no merging, and years in red are years of no collision (no northward motion of the SG). Note that year 2006 is the year of partial merging described in Fig. 7, and is responsible for the peak seen around spiciness values of 6.2 in the histogram of Fig. 9 .

by the total number of points, such that the integral of the PDF over the full range of spiciness values is 1 . The evolution diagrams of the PDF in the time-spiciness space are shown for the $1 / 12^{\circ}$ experiment S12-1 in Fig. 10 (similar results are found in the other experiments). We do not provide here a thorough analysis of the seasonal cycle of the PDF but we focus on the period June to October that is relevant to the collision process.

We first look at years when the collision between the GW and the SG occurs (blue-labelled years in Fig. 10). In these years, the PDF indicates that waters are predominantly "spicy" (large probability to find $\Pi$ ranging between 5.4 and 5.9) during the first 6 months, the period from April to 

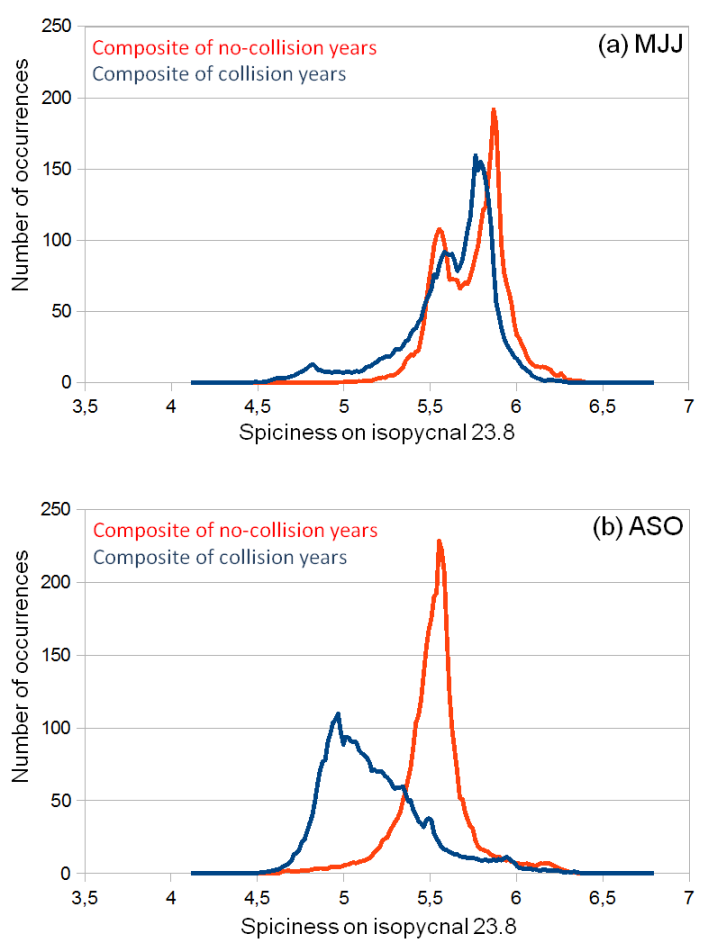

Figure 11. Histograms of spiciness $\Pi$ in the GW box for a composite of years with collision (blue) and a composite of years with no collision (red) in simulation S12-1, (a) for the period May to July (MJJ) and (b) the period August to October (ASO).

June being when the spiciest waters occupy the area. This period corresponds to the onset of the GW. During July, which is the time when the SG makes its northward move, the PDF rapidly shifts toward lower values of spiciness, and from $\mathrm{Au}-$ gust to October the PDF steadily indicates that most waters in the GW box are found with a spiciness ranging between 4.7 and 5.0, typical of SG waters. If we look at years when collision does not occur (years when the SG does not move northward, red-labelled years in Fig. 10), the PDF indicates that almost no water of spiciness less than 5.0 can be found in the region of the GW: in those years, the spiciness is most of the time found in the high range (5.5 to 5.6) typical of early GW waters.

To better discriminate between the years with collisions and the years without we have calculated the histograms of $\Pi$ for two composites, one for years with collision and one for years with no collision (Fig. 11). In the period May to July, which corresponds to when the GW develops to its full strength, the distribution of spiciness in the GW box is basically identical between both composites. In the period August to October, the distribution of spiciness is very different according to the case considered. The spiciness is distributed in a narrow peak around the value of 5.5 when the GW does not interact with the SG, and around a broader peak spreading near the value of 5 in the case of collision. Similar results are found in the other simulations.

\subsection{Socotra Eddy}

The above analysis of the model simulations strongly suggests that the SE that is observed in late August is a residual of the GW after its collision with the SG. However, the analysis of the model solution during the early stage of the Southwest Monsoon (June and July) shows that a SE-like feature (i.e. a coherent patch of anticyclonic vorticity located to the east of Socotra Island) is often present (seven times over the 10 years in S12-2) even before the collision of the GW with the SG begins (Fig. 12). It generally appears in early July when the GW has grown to its full intensity. The generation of this "early" SE appears to be linked to the detachment of the cyclonic bursts and their advection around the GW. The eddy may also appear as an anticyclonic meander of the main current that runs along the northern edge of the GW or as a coherent mesoscale eddy. When the collision of the SG and the GW develops, this early SE is rapidly destroyed or absorbed by the GW. When the SG does not migrate northward and no collision between the SG and the GW occurs, the early SE can live until the end of the monsoon (September, Fig. 4). A similar circulation pattern has been previously reported in analyses of field observations (e.g. Fischer et al., 1996) and was given the name of Socotra Gyre.

Consequently, our model simulations suggest that there is not a unique generation process for the eddies observed to the east of the Socotra Island, but that they result from different ways of interaction of the GW with the topography of the Socotra Island, interactions in which the collision with the Southern Gyre or the dynamics of the bursts has a key role. The water mass properties of the core of the eddy (e.g. spiciness) should be informative to identify which process has been at work in the formation of the eddy.

\section{Conclusions}

Previous efforts to understand the Somali Current and the East African Coastal Current retroflection have focused primarily on the large-scale dynamics governing the seasonal establishment of the large anticyclones, i.e. the Great Whirl and the Southern Gyre, rather than on their fine-scale structures (e.g. the sharp currents and vorticity fronts, smaller flanking cyclones) and their local interactions with the other coherent structures generated within the Somali Current system. This is likely due to the lack of dense in space and time observations. High-resolution model hindcast simulations used herein allowed us to go beyond the view of the large anticyclones only and identify small-scale coherent structures which allows us to some extent to shed light on the dynamics of the Somali Current eddies.

Three eddying global model simulations provided by the DRAKKAR consortium have been used, differing by their resolution $\left(1 / 4\right.$ or $\left.1 / 12^{\circ}\right)$ or by their parametrization (e.g. free-slip or partial-slip boundary condition), or duration 


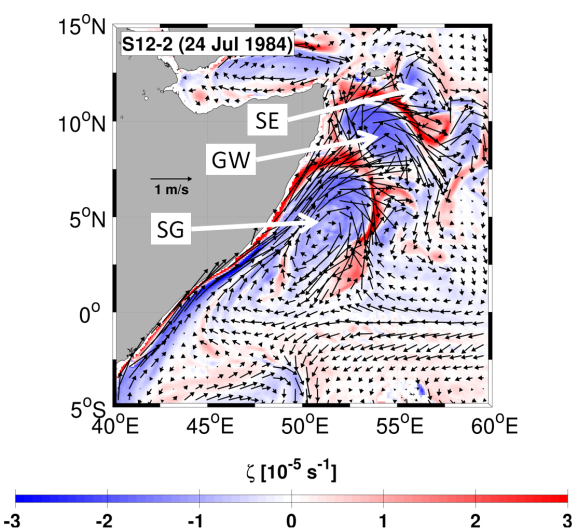

(a) Relative vorticity

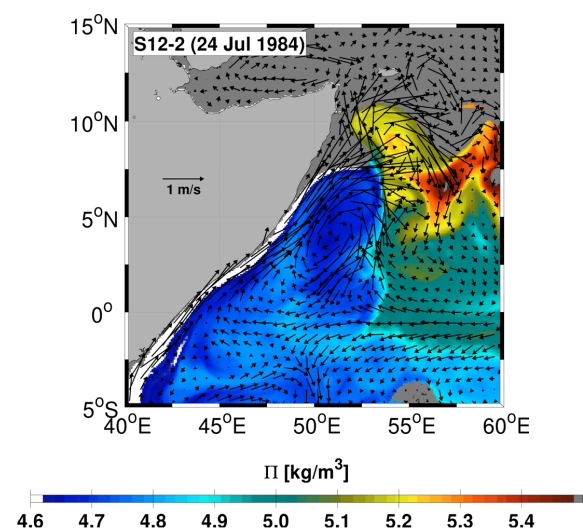

(b) Spiciness

Figure 12. Snapshot on 24 July 1984 of the current (vectors; $\mathrm{m} \mathrm{s}^{-1}$ ) at $50 \mathrm{~m}$ depth superimposed on (a) relative vorticity ( $\zeta$; colour shading; $\mathrm{s}^{-1}$ ) at $50 \mathrm{~m}$ depth and (b) spiciness on isopycnal $\sigma_{0}=23.8$ ( $\Pi$; colour shading; $\mathrm{kg} \mathrm{m}^{-3}$ ) in the $1 / 12^{\circ} \mathrm{S} 12-2$ experiment. SE is Socotra Eddy, GW is Great Whirl, and SG is Southern Gyre.

(from 15 to 30 years), or atmospheric forcing. The analysis of the last 10 years of these simulations first demonstrated the model ability to reproduce with a fairly good realism the major circulation patterns of the circulation in the Northwest Indian Ocean during the Southwest Monsoon. The analysis of 5-day snapshots (over a total of 30 years for all three simulations together) that focused on the generation mechanism of the cyclones flanking the GW and on the nature of interaction between the SG and the GW permits one to follow the time evolution of the dynamics of the Somali eddies.

The Somali eddies described herein appear to be quite similar to eddies shed by low-latitude western boundary currents elsewhere in the global ocean, even though they are among the lowest-latitude and most topographically constrained eddies. For example, the generation mechanism and ultimate structure of the Somali eddies have large similarities with the anticyclonic eddies formed in the western tropical Atlantic by the retroflection of the North Brazil Current (Johns et al., 1990; Barnier et al., 2001). Although the basic formation mechanism and physical characteristics of these lowlatitude eddies are similar, their interactions with the general circulation and regional topography differ substantially. Indeed the GW is unique as it is first generated by remote Rossby waves (see Beal et al., 2013; Akuetevi, 2014) and later amplified by the monsoon winds via an intensification and a retroflection of the Somali Current. Somewhat differently, the SG is the result of pure retroflection of the East African Coastal Current, several retroflection events of that type eventually occurring during the monsoon cycle.

The main findings of this study can be summarized as follows.

- The smaller cyclones flanking the GW identified by Beal and Donohue (2013) in satellite observations are also found around the SG. They are due to the tearing off from the boundary current of intense patches of positive vorticity called bursts that later get organized in coherent cyclones (see Akuetevi and Wirth, 2015). The cyclones often pair with the large anticyclones. In that case they circulate around before finally being sucked up into the anticyclones contributing to their decay or colliding with the boundary current where they are absorbed. They are sometimes detached from the anticyclone to later collapse in the open ocean. These flanking cyclones are likely important drivers in the mixing that occurs offshore of Somalia and into the large anticyclones. They are also largely responsible for the short-time variability of the large anticyclones (as suggested by Beal and Donohue, 2013) and imprint a strong chaotic character to the flow field.

- The interaction between the SG and the GW during July/August (when the Southwest Monsoon is well established) is most frequently a collision without merging (75\% of the cases over 30 years). The outcome is a partial dislocation of the GW which is pushed to the east of Socotra Island to form the SE and gives up its place to the SG. In rare cases the GW can be directly pushed through the Passage of Socotra. Fratantoni et al. (2006) associated this to a particularly intense Southwest Monsoon during August.

- The merging (total or partial) of the SG with the GW cannot be ruled out based on our model simulations. It did not appear as a robust phenomenon in our simulations as it was seen in only one of the simulations that we analysed and not in the two others.

- The merging of the two cold wedges is incidental to the interaction of the GW and the SG since the wedges always merge independently of the interaction process. 
- The SG does not always migrate northward beyond $5^{\circ} \mathrm{N}$. In that rare case (four times over 30 years but seen at least once in every simulation), the GW and the SG do not interact and the evolution of those two eddies is dominated by their interactions with the cyclonic bursts until their dislocation when the monsoon winds vanish.

- Model solutions also exhibit a strong interannual variability of the intra-seasonal fluctuations which is very likely related to the chaotic dynamics of the Somali eddies and in particular to their motion, collapse or collision. The fact that besides the external forcing the chaotic nature of the ocean dynamics contributes substantially to the interannual variability in the Southwest Arabian Sea has already been proposed on the basis of numerical model studies (e.g. Wirth et al., 2002).

The description of the dynamics of the Somali Current system presented here relies on an interpretation of three different global model hindcast simulations. Hence the main scenarios described herein are somewhat robust to those model changes.

It is worth mentioning that within a single simulation, the scenarios described above show a significant year-to-year variability (e.g. Fig. 10). It is quite possible that interannual variations within a given scenario could be influenced by the planetary waves in the Arabian Sea. It is also possible (even likely) that the occurrence of one scenario rather than another in a given year be selected or influenced by Rossby waves or interannual variations of the monsoon winds. These are new issues raised by our study that could not be addressed with the simulations made available to us. Our results also highlighted other phenomena, like the complete disintegration of the GW into small vorticity patches or the merging of part of the $\mathrm{GW}$ into the $\mathrm{SG}$, that are too rare or too specific to a given simulation to assess their robustness to the model parameters that were used in the simulations (e.g. side wall friction).

Model results produced by a single numerical code must be interpreted with caution as they are, to a degree that is often not possible to assess, influenced by specificities of the numerical code used, and the scenarios described here are no exceptions. Therefore it cannot be ruled out that the numerical model used here (i.e. NEMO), although describing the various possible scenarios in a rather robust way, may unrealistically favour one specific scenario (i.e. the collision without merging of the GW and the SG) rather than the others. Indeed, it is somewhat puzzling that our most frequent scenario is not being frequently mentioned in the literature. A reason could be that this event is not as frequent in the real ocean as the model shows, and that the northward motion of the $\mathrm{SG}$ is more often limited below $5^{\circ} \mathrm{N}$. Our models would therefore be biased toward one specific scenario for reasons that still have to be determined but might well be related to the fundamentals of the numerical code (e.g. vertical coordinate system, order of the numerical schemes, etc.) rather than configuration settings (all three configurations used here are favouring the same scenario). But studies of the SG are rare (attention is usually given to the GW) and to our knowledge satellite altimetry has not been applied to the dynamics of this circulation feature. Looking at the model 5-day snapshots of Sea Surface Height (SSH) we found that the SG begins to be detectable in this variable only after it reaches latitudes of 4 to $5^{\circ} \mathrm{N}$ (not shown).

To further investigate this issue, we compared our model output with satellite altimetry data (Figs. 13 and 14). The SSH observational reference is the combination of the AVISO SLA with the annual mean SSH of Maximenko and Niiler (2005) already used in Sect. 3. For the comparison, the SSH of the $1 / 12^{\circ}$ simulation S12-1 has been co-located (in space and time) onto the AVISO data (see Penduff et al., 2011), thus degrading its grid resolution to $1 / 3^{\circ}$ and its time sampling to 7 days. Both data sets have been processed over the same period (12 years from 1993 to 2004).

The comparison of SSH 7-day snapshots over the full period shows that model eddies are generally not in phase with the observations, which strongly suggests that the turbulent dynamics of this region is largely intrinsic and generated by non-linear instabilities of the large-scale circulation. We found a number of events in the AVISO data that are consistent with the collision scenario because they present a strong pattern that is very similar to that of the S12-1 data. An example is shown in Fig. 13 which compares two "look alike" sequences in the simulation and in AVISO.

The model sequence (from 7 July to 4 August 1999) corresponds to a collision between the SG and the GW during which the SG takes the place of the GW. The latter is almost dislocated and ends as a small-size eddy east of Socotra Island (Fig. 13a). The course of this scenario has been clearly established from the fields of vorticity and spiciness of the S12-1 simulation at full resolution. However, the evolution of the model SSH sampled like AVISO could be (falsely) interpreted as a merging of the two eddies: the SSH highs representing the SG and the GW, which are well separated on 7 July, seem to merge into a very intense SSH high between 14 and 27 July at the usual location of the GW. The collision scenario is however confirmed by the sequence shown in Fig. 14a which displays the evolution of the adimensionalized Laplacian of the SSH (a proxy for the relative vorticity of the geostrophic currents). Therefore, the SSH sampled like AVISO alone is not able to discriminate between a merging or a collision. Additional variables (e.g. vorticity and spiciness) are necessary.

The AVISO sequence (28 July to 25 August 2004, Fig. 13b) qualitatively resembles the model sequence, with a lag of 20 days. It could thus be interpreted as a collision. The corresponding vorticity patterns (Fig. 14b) largely reflect the correlation scales used to project the satellite data onto the regular grid. If they do not allow us to distinguish clearly between a merging or a collision, they do not exclude the possibility of a collision event such as the one suggested by the arrows in Fig. 14b. Nevertheless, the AVISO data clearly 

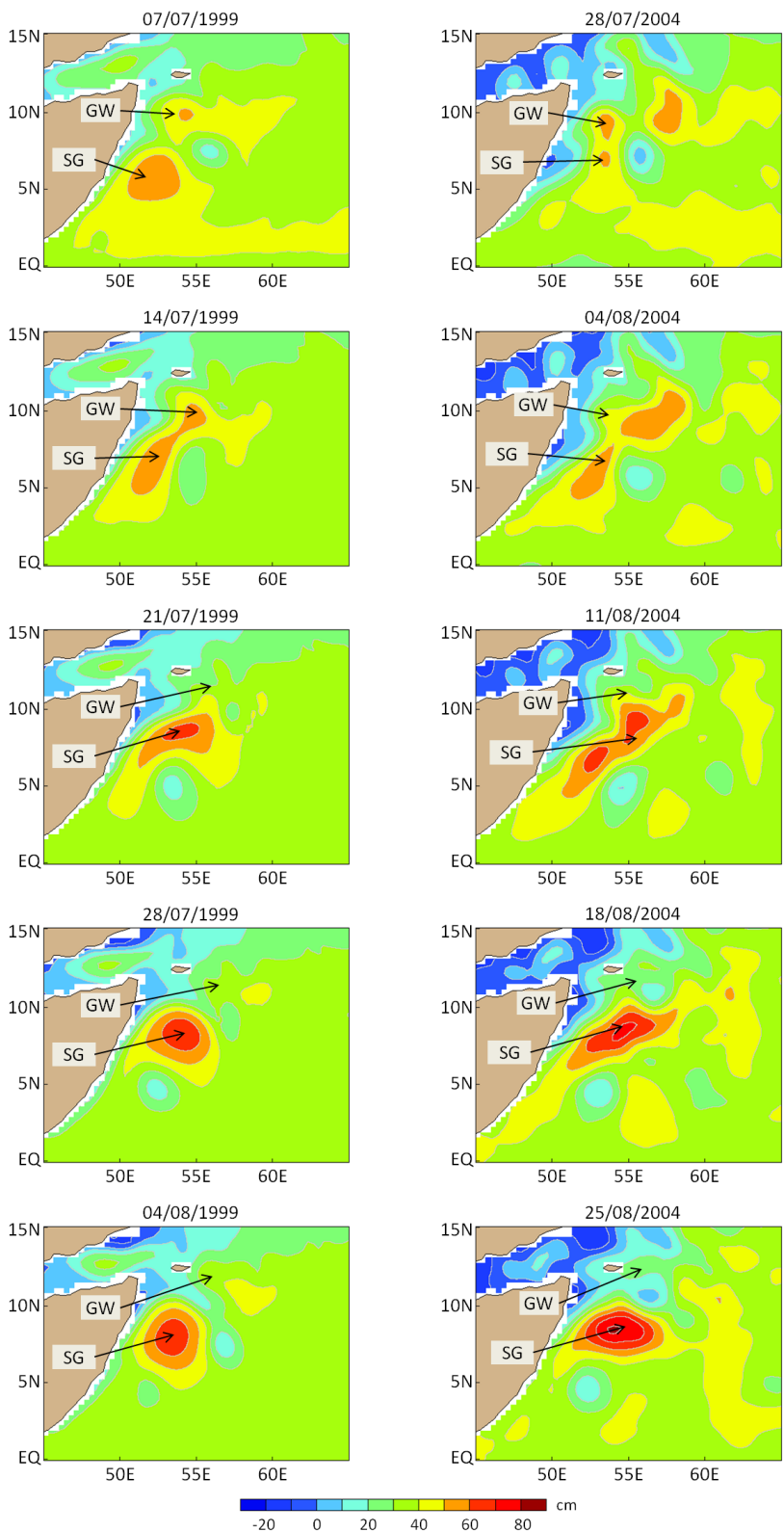

(a) Model

(b) AVISO

Figure 13. Sequences of SSH 7-day snapshots from (a) model simulation S12-1 outputs co-localized in time and space onto the Aviso grid and (b) AVISO sea level anomalies (SLA) data combined with the mean SSH of Maximenko and Niiler (2005). Arrows indicate the location of the Southern Gyre (SG) and the Great Whirl (GW) determined in (a) using the vorticity and spiciness of the model at full resolution, and in (b) to suggest a possible collision scenario.

show a northward move of the SG which finally occupies the place of the GW, but the resolution of the data does not allow us to be certain that the GW was pushed north-eastward in a collision with no merging, or that the two eddies merged. The 7-day sampling of the AVISO data does not seem to be fine enough to distinguish between merging or collision.
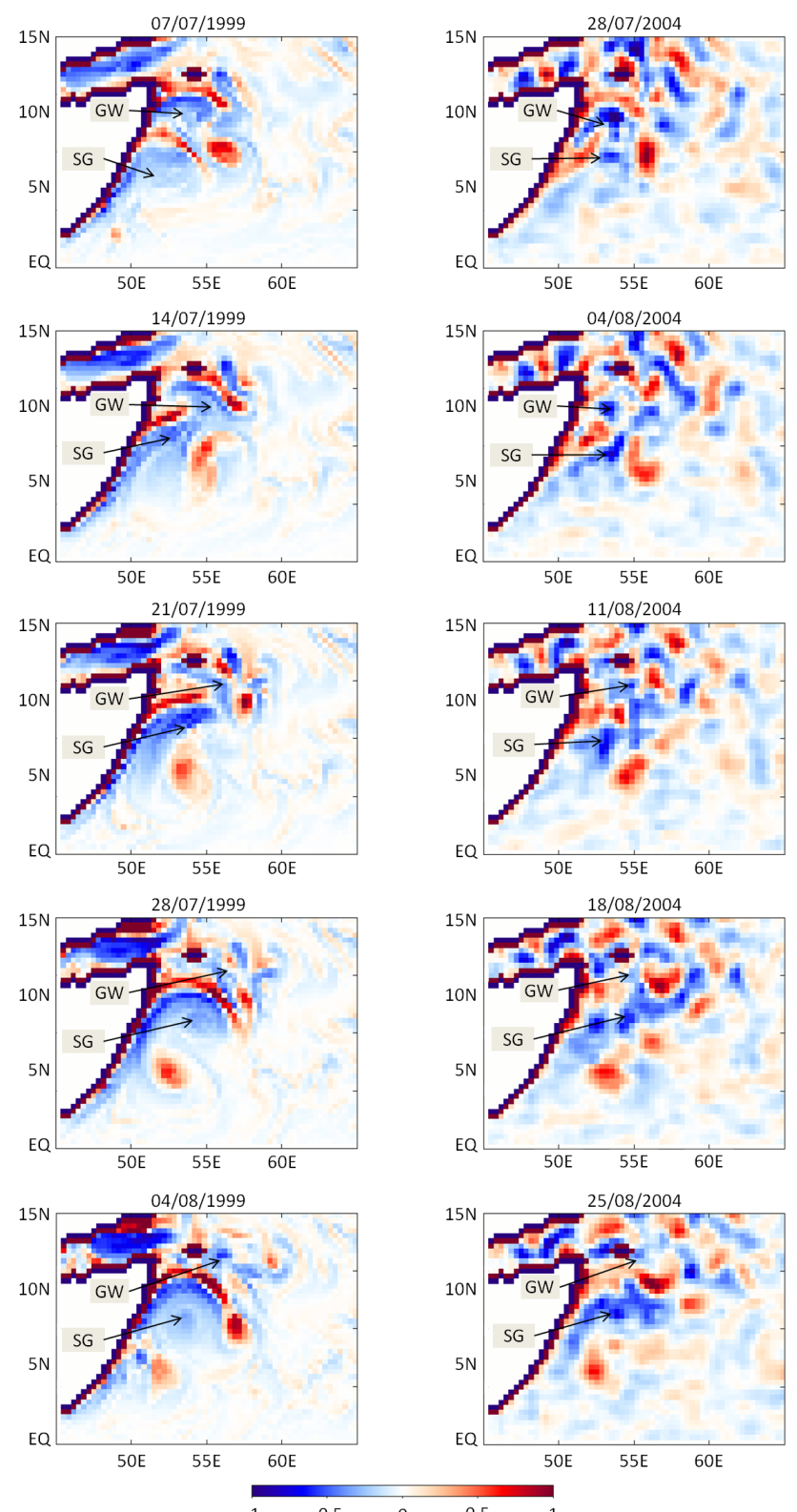

(a) Model

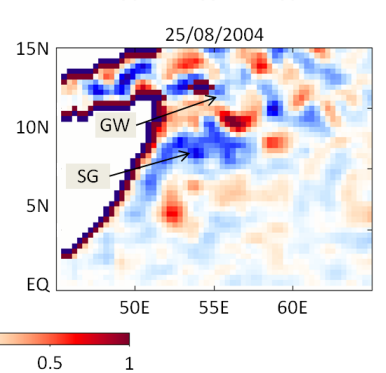

(b) AVISO

Figure 14. Sequences of patterns of a proxy of the relative vorticity from (a) model simulation S12-1 outputs sampled on the Aviso grid, and (b) Aviso altimeter data. The vorticity proxy is calculated as the adimensionalized Laplacian of the 7-day snapshots of SSH shown in Fig. 13 (see text). Arrows indicate the location of the Southern Gyre (SG) and the Great Whirl (GW) determined in (a) using the vorticity and spiciness of the model at full resolution, and in (b) to suggest a possible collision scenario.

We also found a few sequences in the AVISO data that are clearly consistent with a SG that does not migrate northward (again by analogy with the model, not shown). Therefore, the eddy-eddy interaction events seen in the model simulations do show some consistency with the AVISO observation data. 
A simple analogy with a model sequence is certainly not accurate enough to reach a clear conclusion on the process described by the satellite data. It is therefore possible that the present nadir altimetry, which provides heavily filtered/extrapolated maps of SSH every 7 days, does not have the adequate sampling to follow these circulation features with the required level of detail, and that additional observations or different processing taking into account the time evolution of the signal are necessary.

It would be necessary to perform longer simulations, as well as simulations using other ocean models (e.g. other than NEMO) or a broader range of parameters (e.g. advection schemes or subgridscale parametrizations) in order to assess the robustness of our conclusions.

The conclusions of the present study should also be challenged by future studies that may use sufficiently dense (in space and time) satellite observations (e.g. SWOT) or eddyresolving ocean reanalysis, thus giving opportunities to consolidate our findings or to suggest alternative explanations.

Acknowledgements. The authors were supported by French Ministère de l'Enseignement Supérieur et de la Recherche, Centre National de la Recherche Scientifique (CNRS) and Université de Grenoble-Alpes (UGA). This work is a contribution to the DRAKKAR GDRI. It was granted access to HPC resources under the allocations x2013-010727 and x2014-010727 attributed by GENCI to DRAKKAR, simulations being carried out at both the IDRIS and CINES supercomputer national facilities. Research leading to these results also benefited from some support provided by GMMC to DRAKKAR and by Centre National d'Etudes Spatiales (CNES). The altimeter products were produced by SSALTO/DUACS and distributed by AVISO, with support from CNES (http://www.aviso.altimetry.fr/duacs/).

Edited by: M. Hecht

\section{References}

Akuetevi, C. Q. C.: Dynamics of turbulent western boundary currents at low latitude, a numerical study, $\mathrm{PhD}$ thesis, Université Joseph-Fourier-Grenoble I, available at: http://lgge.osug.fr/ meom/Publications/pdf/these_akuetevi.pdf (last access: 20 January 2016), 2014.

Akuetevi, C. Q. C. and Wirth, A.: Dynamics of turbulent westernboundary currents at low latitude in a shallow-water model, Ocean Sci., 11, 471-481, doi:10.5194/os-11-471-2015, 2015.

Balmaseda, M., Hernandez, F., Storto, A., Palmer, M., Shi, L., Smith, G., Toyoda, T., Valdivieso, M., Alves, O., Barnier, B., Boyer, T., Chang, Y.-S., Chepurin, G. A., Ferry, N., Forget, G., Fujii, Y., Good, S., Guinehut, S., Haines, K., Ishikawa, Y., Keeley, S., Köhl, A., Lee, T., Martin, M., Masina, S., Masuda, S., Meyssignac, B., Mogensen, K., Parent, L., Peterson, D., Yin, Y., Vernieres, G., Wang, X., Waters, J., Wedd, R., Wang, O., Xue, Y., Chevallier, M., Lemieux, J.-F., Dupont, F., Kuragano, T., Kamachi, M., Awaji, T., Cantalbiano, A., Wilmer-Becker,
K., and Gaillard, F.: The Ocean Reanalyses Intercomparison Project (ORA-IP), J. Operat. Oceanogr., 8, 80-97, 2015.

Barnier, B., Reynaud, T., Beckmann, A., Böning, C., Molines, J.M., Barnard, S., and Jia, Y.: On the seasonal variability and eddies in the North Brazil Current: insights from model intercomparison experiments, Prog. Oceanogr., 48, 195-230, 2001.

Barnier, B., Madec, G., Pendu , T., Molines, J.-M., Treguier, A.-M., Le Sommer, J., Beckmann, A., Biastoch, A., Böning, C., Dengg, J., Derval, C., Durand, E., Gulev, S., Remy, E., Talandier, C., Theetten, S., Maltrud, M., McClean, J., De Cuevas, B.: Impact of partial steps and momentum advection schemes in a global ocean circulation model at eddy-permitting resolution, Ocean Dynam., 56, 543-567, 2006.

Beal, L. M. and Donohue, K. A.: The Great Whirl: Observations of its seasonal development and interannual variability, J. Geophys. Res.-Oceans, 118, 1-13, 2013.

Beal, L. M., Hormann, V., Lumpkin, R., and Foltz, G.: The response of the surface circulation of the Arabian Sea to monsoonal forcing, J. Phys. Oceanogr., 43, 2008-2022, 2013.

Böning C. W., Dieterich, C., Barnier, B., and Jia, Y.: Seasonal cycle of meridional heat transport in the subtropical North Atlantic: a model intercomparison in relation to observations near $25^{\circ} \mathrm{N}$, Prog. Oceanogr., 48, 231-253, 2001.

Brodeau, L., Barnier, B., Treguier, A.-M., Penduff, T., and Gulev, S.: An ERA40-based atmospheric forcing for global ocean circulation models, Ocean Modell., 31, 88-104, 2010.

Dee, D., Uppala, S., Simmons, A., Berrisford, P., Poli, P., Kobayashi, S., Andrae, U., Balmaseda, M., Balsamo, G., Bauer, P., Bechtold, P., Beljaars, A. C. M., van de Berg, L., Bidlot, J., Bormann, N., Delsol, C., Dragani, R., Fuentes, M., Geer, A. J., Haimberger, L., Healy, S. B., Hersbach, H., Holm, E. V., Isaksen, L., Kallberg, P., Köhler, M., Matricardi, M., McNally, A. P., Monge-Sanz, B. M., Morcrette, J.-J., Park, B.-K., Peubey, C., de Rosnay, P., Tavolato, C., Thépaut, J.-N., and Vitart, F.: The ERA-Interim reanalysis: configuration and performance of the data assimilation system, Q. J. Roy. Meteorol. Soc., 137, 553597, 2011.

Deshayes, J., Tréguier, A.-M., Barnier, B., Lecointre, A., Sommer, J. L., Molines, J.-M., Pendu, T., Bourdallé-Badie, R., Drillet, Y., Garric, G., Benshila, R., Madec, G., Biastoch, A., Böning, C. W., Scheinert, M., Coward, A. C., and Hirschi, J. J.-M.: Oceanic hindcast simulations at high resolution suggest that the Atlantic MOC is bistable, Geophys. Res. Lett., 40, 3069-3073, 2013.

DRAKKAR-Group, Barnier, B., Brodeau, L., Le Sommer, J., Molines, J.-M., Penduff, T., Theetten, S., Treguier, A.-M., Madec, G., Biastoch, A., Böning, C., Dengg, J., Gulev, S., BourdalléBadie, R., Chanut, J., Garric, G., Alderson, S., Coward, A., de Cuevas, B., New, A. U., Haines, K., Smith, G., Myers, P., Drijfhout, S., Hazeleger, W., and Severijns, C.: Eddy-permitting Ocean Circulation Hindcasts of past decades, Clivar Exchange Newslett., 12, 8-10, 2007.

DRAKKAR Group, Treguier, A.-M., Barnier, B., Blaker, A., Biastoch, A., Böning, C., Coward, A., Deshayes, J., Duchez, A., Hirschi, J., Le Sommer, J., Madec, G., Maze, G., Molines, J.M., New, A., Penduff, T., Scheinert, M., and Talandier, C.: DRAKKAR: developing high resolution ocean components for European Earth system models, Exchanges, Clivar Newslett., 65, 19, 2014. 
Evans, R. H. and Brown, O. B.: Propagation of thermal fronts in the Somali Current system, Deep-Sea Res. Pt. A, 28, 521-527, 1981.

Fischer, J., Schott, F., and Stramma, L.: Currents and transports of the Great Whirl-Socotra Gyre system during the summer monsoon, August 1993, J. Geophys. Res., 101, 3573-3587, 1996.

Flament, P.: A state variable for characterizing water masses and their diffusive stability: spiciness, Prog. Oceanogr., 54, 493-501, 2002.

Fratantoni, D. M., Bower, A. S., Johns, W. E., and Peters, H.: Somali Current rings in the eastern Gulf of Aden, J. Geophys. Res.Oceans, 111, C09039, doi:10.1029/2005JC003338, 2006.

Jensen, T. G.: Modeling the seasonal undercurrents in the Somali Current system, J. Geophys. Res.-Oceans, 96, 22151-22167, 1991.

Johns, W. E., Lee, T. N., Schott, F. A., Zantopp, R. J., and Evans, R. H.: The North Brazil Current retroflection: seasonal structure and eddy variability, J. Geophys. Res.-Oceans, 95, 22103-22120, 1990.

Large, W. and Yeager, S.: The global climatology of an interannually varying air-sea flux data set, Clim. Dynam., 33, 341-364, 2009.

Lecointre, A., Molines, J.-M., and Barnier, B.: Definition of the interannual experiment ORCA12.L75-MAL83, (1978-1982) and ORCA12.L46-MAL83/84/85 (19781982 and 1978-1992), Technical report LEGI-DRA-2310-2011, http://www.drakkar-ocean.eu/publications/reports/ rapport-run-orca12.175-mal83.pdf (last access: 20 January 2016), 2011a.

Lecointre, A., Molines, J.-M., and Barnier, B.: Definition of the interannual experiment ORCA12.L46-MAL95, 1989-2007, Drakkar Technical Report LEGI-DRA-23-102011, http://www.drakkar-ocean.eu/publications/reports/ rapport-run-orca12.146-mal95.pdf (last access: 20 January 2016), 2011b.

Lumpkin, R. and Johnson, G. C.: Global ocean surface velocities from drifters: Mean, variance, El Nino-Southern Oscillation response, and seasonal cycle, J. Geophys. Res., 118, 2992-3006, doi:10.1002/jgrc.20210, 2013.

Luther, M. E. and O'Brien, J. J.: Modelling the Variability in the Somali Current, Mesoscale/Synoptic Coherent Structures in Geophysical Turbulence, Elsevier, Amsterdam, 373-386, 1989.

Madec, G.: NEMO ocean engine, Institut Pierre-Simon Laplace (IPSL), Paris, 2008.

Maltrud, M. E. and McClean, J. L.: An eddy resolving global 1/10 ocean simulation, Ocean Modell., 8, 31-54, 2005.

Maximenko, N. A. and Niiler, P. P.: Hybrid decade-mean global sea level with mesoscale resolution, in: Recent Advances in Marine Science and Technology, 2004, edited by: Saxena, N., PACON International, Honolulu, 55-59, 2005.

Maze, G., Deshayes, J., Marshall, J., Tréguier, A.-M., Chronis, A., and Vollmer, L.: Surface vertical PV fluxes and subtropical mode water formation in an eddy-resolving numerical simulation, Deep-Sea Res. Pt. II, 91, 128-138, 2013.

Megann, A., Storkey, D., Aksenov, Y., Alderson, S., Calvert, D., Graham, T., Hyder, P., Siddorn, J., and Sinha, B.: GO5.0: the joint NERC-Met Office NEMO global ocean model for use in coupled and forced applications, Geosci. Model Dev., 7, 10691092, doi:10.5194/gmd-7-1069-2014, 2014.
Penduff, T., Juza, M., Barnier, B., Zika, J., Dewar, W. K., Treguier, A.-M., Molines, J.-M., and Audiffren, N.: Sea-level expression of intrinsic and forced ocean variabilities at interannual time scales, J. Climate, 24, 5652-5670, doi:10.1175/JCLI-D-1100077.1, 2011.

Robinson, S. K.: Coherent motions in the turbulent boundary layer, Ann. Rev. Fluid Mech., 23, 601-639, 1991.

Schott, F. A. and McCreary, J. J. P.: The monsoon circulation of the Indian Ocean, Prog. Oceanogr., 51, 1-123, 2001.

Schott, F. A., Fischer, J., Garternicht, U., and Quadfasel, D.: Summer monsoon response of the northern Somali Current, Geophys Res. Lett., 24, 2565-2568, 1997.

Schott, F. A., Xie, S.-P., and McCreary, J. P: Indian Ocean circulation and climate variability, Rev. Geophys., 47, RG1002, doi:10.1029/2007RG000245, 2009.

Sérazin, G., Penduff, T., Grégorio, S., Barnier, B., Molines, J.-M., and Terray, L.: Intrinsic Variability of Sea Level from Global $1 / 12^{\circ}$ Ocean Simulations: Spatio temporal Scales, J. Climate, 28, 4279-4292, doi:10.1175/JCLI-D-14-00554.1, 2015.

Swallow, J. C., Molinari, R. L., Bruce, J. G., Brown, O. B., and Evans, R. H.: Development of near-surface flow pattern and water mass distribution in the Somali Basin in response to the Southwest Monsoon of 1979, J. Phys. Oceanogr., 13, 1398-1415, 1983.

Treguier, A. M., Deshayes, J., Le Sommer, J., Lique, C., Madec, G., Penduff, T., Molines, J.-M., Barnier, B., Bourdalle-Badie, R., and Talandier, C.: Meridional transport of salt in the global ocean from an eddy-resolving model, Ocean Sci., 10, 243-255, doi:10.5194/os-10-243-2014, 2014.

Valcke, S. and Verron, J.: Interactions of baroclinic isolated vortices: The dominant effect of shielding, J. Phys. Oceanogr., 27, 524-541, 1997.

Vic, C., Roullet, G., Carton, X., and Capet, X.: Mesoscale dynamics in the Arabian Sea and a focus on the Great Whirl life cycle: A numerical investigation using ROMS, J. Geophys. Res.-Oceans, 119, 6422-6443, 2014.

Willebrand, J., Barnier, B., Böning, C., Dieterich, C., Killworth, P., LeProvost, C., Jia, Y., Molines, J. M., and New, A. L.: Circulation characteristics in three eddy-permitting models of the North Atlantic, Prog. Oceanogr., 48, 123-162, 2001.

Williams, K. D., Harris, C. M., Bodas-Salcedo, A., Camp, J., Comer, R. E., Copsey, D., Fereday, D., Graham, T., Hill, R., Hinton, T., Hyder, P., Ineson, S., Masato, G., Milton, S. F., Roberts, M. J., Rowell, D. P., Sanchez, C., Shelly, A., Sinha, B., Walters, D. N., West, A., Woollings, T., and Xavier, P. K.: The Met Office Global Coupled model 2.0 (GC2) configuration, Geosci. Model Dev., 8, 1509-1524, doi:10.5194/gmd-8-1509-2015, 2015.

Wirth, A., Willebrand, J., and Schott, F.: Variability of the Great Whirl from observations and models, Deep-Sea Res. Pt. II, 49, 1279-1295, 2002. 